\title{
Publication records of Australian accounting and finance faculty promoted to full professor, set within an international context
}

\author{
Alan Goodacre $^{\mathrm{a}}$ (D), Clive Gaunt ${ }^{\mathrm{b}}$ (D), Darren Henry ${ }^{\mathrm{c}}$ (D) \\ a Accounting and Finance Division, Stirling Management School, University of Stirling, Stirling, \\ $U K$ \\ ${ }^{\mathrm{b}}$ Queensland University Business School, Brisbane, Queensland, \\ ${ }^{\mathrm{c}}$ La Trobe University, Melbourne, Victoria, Australia
}

\begin{abstract}
Australian accounting and finance faculty promoted to full professor required a median 15 papers in ABDC-listed journals, with 7 at the highest $\mathrm{A}^{*} / \mathrm{A}$ quality levels. Promotees were typically 44 years old, with 14 years' academic experience including 9 years post-PhD. Neither gender nor whether promotion was internal/external seemed to affect promotion requirements. Finance professors typically had more publications than accounting professors, though not at the higher quality levels; however, accounting promotees had greater academic experience but a shorter period post-PhD. Female promotees were typically older than males. Both the volume and quality of pre-promotion publications have increased over time.
\end{abstract}

Key words: Internationalisation; Productivity; Professor; Promotion; Publication

JEL classification: I23, M40, G00, J24, J61

doi: $10.1111 /$ acfi. 12695

We would like to thank Carolyn Fowler (discussant) and other participants at the AFAANZ 2016 (Queensland) and BAFA 2016 (Bath) annual conferences, together with anonymous reviewers, for helpful comments on earlier versions of this paper. The financial support of The Carnegie Trust (for Alan Goodacre) is gratefully acknowledged.

Please address correspondence to Alan Goodacre via email: alan.goodacre@stir.ac.uk

(C) 2020 The Authors. Accounting \& Finance published by John Wiley \& Sons Australia, Ltd on behalf of Accounting and Finance Association of Australia and New Zealand

This is an open access article under the terms of the Creative Commons Attribution-NonCommerc ial-NoDerivs License, which permits use and distribution in any medium, provided the original work is properly cited, the use is non-commercial and no modifications or adaptations are made. 


\section{Introduction}

Publications and subsequent citations are key indicators of academic reputation and are subject to evaluation for various academic decisions. Such decisions include those for appointment or promotion and consideration for tenure (or completion of probation). Appreciation of publication expectations represents a challenge for individual academics who are seeking promotion. Given the increasing tendency for larger, more diverse, academic groupings within universities, the challenge is exacerbated when seeking to evaluate, and perhaps rank, academics from different disciplines with potentially widely differing norms (Swanson, 2004). Prior evidence on promotion 'benchmarks' also suggests that there are substantial cross-country differences (e.g., between the US and the UK: Beattie and Goodacre, 2012). This potentially adds a further dimension to the challenge in light of increased internationalisation of the academic community (Teichler et al., 2013), especially for the non-local 'immigrant' academic seeking appointment and/or promotion in a different country. With one known exception, prior studies of promotion benchmarks in accounting and finance cover the US (e.g. Fishe, 1998; Glover et al., 2006, 2012 and references therein); the exception is for the UK (Beattie and Goodacre, 2012).

While Chan (1996) has developed a theory to analyse the choice between internal promotion and external appointment (using an economic contest model framework), Beattie and Goodacre (2012, pp. 204-205) note that no generic 'theory of promotion' exists, suggesting that this may reflect variations in relevant criteria across different occupations. Rather, they frame their UK promotion study within the context of the theory of academic identity. They note that many aspects of academic work and identity have been affected by increased managerialism in the academic environment and highlight the exploration by Henkel (2005) of its impact on academic identity and autonomy. Traditionally, it has usually been argued that academics identify more with their relevant discipline than with their employing institution. However, in disciplines such as accounting and finance with relatively 'fluid' epistemic boundaries, one might expect the 'discipline' impact on identity to be weaker. Further, institutions often seem to have greater control over appointments, evaluation and rewards (Henkel, 2005). In light of this tension, Beattie and Goodacre (2012, p. 198) argue that 'consideration of the promotion process has the potential to shed light on the relative contributions of 'discipline' and 'institution' to 'academic identity'. Perhaps surprisingly, their results suggest that the UK accounting and finance discipline(s) seemed to maintain a fair degree of influence in the promotion process.

The present paper replicates and extends the Beattie and Goodacre (2012) study within the Australian accounting and finance (A\&F) discipline. Several elements within the Australian environment provide an interesting context and justification for the present paper.

(C) 2020 The Authors. Accounting \& Finance published by John Wiley \& Sons Australia, Ltd on behalf of Accounting and Finance Association of Australia and New Zealand 
First, the Australian university sector has developed somewhat differently from either the UK or US sectors, influenced by various factors including its relative proximity to Asia. In his discussion of competition in higher education, Marginson (2006, pp. 2-3) suggests that Australia is interesting because 'it is an intermediate national case: stronger in cross-border teaching than research; and located somewhere between the Ivy League institutions in the USA and UK, the research universities of Western Europe, and the Asian nations which provide the most foreign students'. Further, the continuing emergence of 'the enterprise university' as the major institutional form in Australia has led to a decline in the role of academic disciplines in governance, with institutional managers adopting various techniques to curb the power of disciplines (Marginson and Considine, 2000). These characteristics mean that Australia is a fascinating environment in which to study further the promotion issue, especially in considering the theoretical debate about the relative influence of universities and academic disciplinary 'communities'. For example, it has the potential to help clarify whether the somewhat unexpected UK evidence (Beattie and Goodacre, 2012) might be location- and/or time-specific.

Second, there are subtle differences between academic ranks in Australia and in other countries. In Australia, academics are appointed at one of five levels (A-E). One illustration of the cross-country differences is the relatively infrequent use of level D appointments (Associate Professor/Reader) in the UK. While the title of Reader carries kudos, the UK pay scale for this level has traditionally been identical to that for Senior Lecturer, reducing the attractiveness of the Reader designation. Indeed, only 4 percent of the research-oriented accounting and finance community had this title (Beattie and Goodacre, 2004) in contrast with 14 percent in Australia (ERA, 2018). Given the (mainly) national pay scales employed in the UK, it has been a challenge to financially reward academics who demonstrate quickly developing research excellence, but one mechanism is 'early' promotion to full professor; it can be argued that this is unnecessary in Australia as promotion to Associate Professor can facilitate financial (and kudos-related) recognition. ${ }^{1}$

Third, inter-country differences in the role and impact of research assessment have the potential to affect criteria for promotion. Unlike many countries, the US has no direct equivalent of formal research assessments of universities (Von Tunzelmann and Mbula, 2003); there is less need for such given that universities are either private or funded by the federal states. By contrast, the UK government funds university research partly via a block grant that is based on the results of formal research assessment. The UK began its process of formal evaluation of university research in 1986 and has now been through six

\footnotetext{
${ }^{1}$ The percentage of academics at level $\mathrm{E}$ in the UK (Australia) was 25 percent (18 percent), making very similar totals of 29 percent ( 32 percent) across the two 'professor' levels; this could be construed as indicative evidence of the 'early promotion in the UK' argument.
}

(C) 2020 The Authors. Accounting \& Finance published by John Wiley \& Sons Australia, Ltd on behalf of Accounting and Finance Association of Australia and New Zealand 
cycles of assessment. Australia began the process somewhat later and is now in its second 'regime' of university research assessment. The first, the Research Quality Framework (RQF), was announced in 2004 and after a short period of operation was replaced by the launch of the second, the Excellence in Research for Australia (ERA) in 2008, which was fully implemented in 2010. ERA effected a change from the prior emphasis on quantity of research outputs to greater focus on high-level journal outputs and external research grants. Four rounds of ERA have now been completed (2010, 2012, 2015 and 2018). The Australian Government also introduced a national impact and engagement assessment' of university research, carried out by the Australian Research Council as a companion exercise to ERA in 2018 (ERA, 2018).

Finally, issues relating to insufficient supply of academic labour, together with related academic staff internationalisation policies have the potential to influence promotion practices. The actual and potential future shortage of accounting academics is acknowledged internationally (e.g. US: Plumlee et al., 2006; UK: Smith and Urquhart, 2018; Australia: Irvine et al., 2010). While there is less evidence of such shortage in finance, the large starting salaries offered to new finance academics in the US (AACSB, 2007) suggest that recruitment in finance is similarly challenging. The timing and duration of such shortages and/or the amelioration policies adopted are expected to differ across countries. To the extent that these differences occur, the potential impact on promotion prospects and requirements will also vary. Similarly, variations in the timing and rate of growth in the internationalisation of academic staff may also affect promotion characteristics.

The current paper investigates promotions to full professor in accounting and finance at Australian universities. It contributes by providing for the firsttime publication benchmarks that can be useful in recruitment and promotion decisions, especially those requiring comparisons across disciplinary boundaries. It also contributes by examining factors that might influence promotion hurdles. Finally, comparison with prior research in the US (Fishe, 1998; Glover et al., 2006, 2012) and the UK (Beattie and Goodacre, 2012) enables a preliminary assessment of the additional challenges faced by 'non-local' academics. The results are based on data sourced initially by email survey of academics, extended by detailed analysis of alternative publicly available sources. In contrast with some prior studies (Glover et al., 2006, 2012), it does not restrict analysis to a pre-selected set of elite journals but considers all journal outputs. Pre-promotion publication portfolios are examined to assess whether these have changed over time, whether there are differences across institution peer group, sub-discipline, gender, internal versus external promotion, and the impact of co-authorship; cross-country differences are also investigated. Separate results are reported along various dimensions (e.g. for a recent time period) to facilitate more appropriate benchmarking.

Farrell (2009) provides a very useful summary of the policies, conventions and practices concerning the use of the title 'Professor' in Australia. Typically, 
to be appointed Professor (level E) the individual must demonstrate a university's minimum standard relating to eminence, distinction and leadership. While occasionally, the title of professor may be related to appointment in a senior management position without the need for an extensive academic record or a $\mathrm{PhD}$, research success arguably remains the most important attribute (Parker et al., 1998; Hermanson, 2008). However, research outputs alone are unlikely to be sufficient for promotion (Fishe, 1998); universities typically expect more, including contributions of leadership in teaching and management. By way of illustration, the current generic 'Minimum standards for academic levels' (MSALs) for level E in Australia typically include the following (or similar):

A Level E academic will provide leadership and foster excellence in research, teaching and policy development in the academic discipline within the institution and within the community, professional, commercial or industrial sectors. A Level E academic will have attained recognition as an eminent authority in his or her discipline, will have achieved distinction at the national level and may be required to have achieved distinction at the international level. A Level E academic will make original, innovative and distinguished contributions to scholarship, researching and teaching in his or her discipline. He or she will make a commensurate contribution to the work of the institution (University of South Australia, 2019; La Trobe University, 2020).

Some universities have their own versions with subtly different emphases (e.g. distinction at international rather than national level) and/or provide further details of how the general statements might be interpreted and acceptable evidence expected in support of claims of appropriate merit. A brief analysis of published information currently available from several universities, ${ }^{2}$ including details of one current recruitment document, highlighted the following. In research, while high-quality academic outputs are of major importance, other significant factors are identified including (usually) the importance of a track record of research funding, of research student supervision, of building/ coordinating research teams and of research impact. More generally, the documents suggest a strong emphasis on leadership, mentoring of junior colleagues, excellence in teaching, engagement and active service participation within the university and externally, and on promotion of the profile of the university.

The current study considers just one element of the broader purview of promotion expectations: research journal publications. While this measure is likely to be of major importance, the results need to be interpreted with caution given the other significant attributes that represent 'omitted variables' in this

\footnotetext{
${ }^{2} \mathrm{~A}$ convenience sample including several suggested by an anonymous reviewer (for which the authors are grateful): University of Adelaide, Flinders University, La Trobe University, University of Melbourne, University of South Australia, University of Western Australia.
}

(C) 2020 The Authors. Accounting \& Finance published by John Wiley \& Sons Australia, Ltd on behalf of Accounting and Finance Association of Australia and New Zealand 
paper. This is a limitation of this and similar studies and one which is worthy of future research. ${ }^{3}$

\section{Prior literature}

A number of prior papers have sought to describe and explain research productivity of accounting and finance staff in Australia (Durden et al., 1999; Hodgson et al., 1999; Wilkinson et al., 2003; Tower et al., 2005). Such studies are, of course, not without criticism (Milne et al., 1999) but perhaps reflect the argument that contemporary academics 'no longer engage in the pursuit of knowledge, rather the pursuit of journal scores' (Guthrie and Parker, 2014). Recently, Chan et al. (2012) analysed accounting and finance research productivity in Australia and New Zealand for the period 1991-2010. They found that output steadily increased over the period and that productive authors were able to move to alternative posts. Further, they noted the difficulty for accounting and finance staff to build a portfolio of publications. They identified that 5 (11) outputs in their set of 48 high-quality journals would place an author in the top 15th (5th) percentile.

While there have been several prior US studies of promotion benchmarks in accounting, only one considers the finance discipline. Fishe (1998) investigated promotions to full (and associate) professor of finance and found that promotees in highly ranked departments typically had a higher proportion of quality outputs and a larger number of citations. While the overall number of publications was not significantly smaller in lower-ranked departments, promotees were able to substitute a proportion of high-quality outputs with those of lower quality. The two most recent papers considering accounting academic promotions are related. Glover et al. (2006) examined publications of accounting faculty promoted to full (and associate) professor at the top 75 US accounting research programmes for the 1995-2003 period. They also found that the number of quality publications at the time of promotion is positively associated with the perceived quality of the institution and that publication quantity compensated for reduced quality in lower level institutions. Their later study, updated for the 2004-2009 period (Glover et al., 2012), found that promotees had more publications at the time of promotion than in the earlier period. This suggests that publication requirements for promotion may have increased over time, in part reflecting an observed longer period between PhD and promotion, as well as increased space availability in the top journals and a general increase in co-authored publication numbers.

Glover et al. (2006) motivated their study primarily as a response to two challenges they experienced while serving on promotion and tenure committees. First, data on discipline-specific publication rates are often anecdotal and

\footnotetext{
${ }^{3}$ The authors are grateful to an anonymous reviewer for suggesting the above additional analysis and emphasis.
} 
unreliable. Second, accounting academics typically have a smaller number of publications in promotion portfolios compared with other business school disciplines. Empirical evidence of this is provided in two similar studies (Buchheit et al., 2002; Swanson, 2004), which compare the publication quality norms across the four business disciplines of accounting, finance, management and marketing. Both found that differences exist in quality norms across disciplines and that accounting has lower top-tier publication rates than other disciplines. Promotion and new appointment decisions are frequently made at Business School (or similar, even university) level. This assumes that panel members can evaluate publication records of staff from academic disciplines other than their own. Unfortunately, this is rarely the case. Within cognate disciplines across the broad business area, even well-read scholars have limited knowledge about journals outside their own field (Henderson et al., 1990); and knowledge of journals beyond cognate groupings is likely to be minimal. Discipline-specific promotion benchmarks can help alleviate such difficulties.

The only known non-US study on promotion benchmarks in accounting and finance is the UK-based study by Beattie and Goodacre (2012). They found that an average of nine papers in journals listed by the Association of Business Schools (ABS) (Harvey et al., 2008), with 5 at the highest $3 * / 4 *$ quality levels in a portfolio total of 20 outputs, were required for promotion. The portfolio total includes non-serial publications such as monographs, book chapters and professional reports. They also found that publication requirements seem to have increased over time and provided some evidence of higher hurdles for internal promotions. However, there was no evidence of promotion differences related to gender, or between the accounting and finance sub-disciplines, or related to institution research intensity. Output quantity did not seem to substitute for quality and sole authorship did not seem to have a significant impact on promotion portfolios. Their comparison with the US-equivalent study (Glover et al., 2006) documented major differences in journal prevalence, suggestive of underlying geographically based paradigm distinctions. Journalranking studies have also noted major geographical differences in journal quality perceptions, especially of journals outside the very top tier (Ballas and Theoharakis, 2003; Oltheten et al., 2005). Thus, prior evidence suggests that promotion benchmarks need to be geographic- as well as discipline-specific, lending support to the current Australia-specific focus.

In the mid-1990s, business was apparently the least international of all the academic disciplines (Welch, 1997, p. 330) and Lukka and Kasanen (1996) concluded that the accounting research community 'is a rather local discipline'. Since then, international competition has increased, both generally and within the academic environment. Faced with growing demand for academics and an ageing workforce, universities in Australia (and elsewhere) face a potential shortfall of qualified staff (Coates et al., 2009), which has seen an internationalisation of the academic profession (Teichler et al., 2013). The academic profession in Australia can be described as highly international and mobile, 
with significant numbers of academic staff departing to and arriving from overseas. While traditional sources (New Zealand, the US, UK and Other Europe) continued to be important, Asia was the most important source, accounting for 71 percent of the net gain of academic migrants in 2006, with China and India the major net contributors (Hugo, 2008). However, academic migration can lead to challenging workplace transition issues including those related to how previous experience and qualifications, of crucial importance to career advancement, might be valued in the new academic environment (Balasooriya et al., 2014).

While gender is not a major focus of the current paper, it may be an important factor when seeking to interpret and discuss the results. Prior research has considered gender in the context of academic leadership and promotion in light of the observed lack of women in senior academic positions. For context, at 31 March 2017, the percentage of women at professor (level E) and associate professor (level D) across accounting and finance was just 22 percent and 30 percent, respectively (ERA, 2018). A brief summary based on a selection of papers set within the Australian context follows. There seems to be a general consensus that policy changes have reduced some of the more obvious elements of bias and discrimination. For example, Winchester et al. (2006) argue that under-representation of senior women is "not a result of poor policy or erratic implementation, but is a deep-seated cultural issue requiring cultural and generational change'. Similarly, Probert (2005) found that under-representation was not due to direct discrimination or bias in appointments, promotions or workloads. She suggests inter alia a greater need to focus on the impact of the household: 'women's ability to devote time to paid work is the outcome of a complex and highly gendered set of negotiations and compromises within the household'. Pyke (2013) suggests that women may choose not to seek promotion but this is often due to circumstances rather than unfettered personal choice. In particular, women appeared to be 'slowed down, in ways that men are not' by various factors such as discontinuous and interrupted career paths, care responsibilities, absence of support and encouragement or even downright discouraging work environments. However, evidence from Kahn (2012) suggests that some career interruptions (e.g., maternity leave) did not seem to hamper promotion prospects. She also notes that women may be less mobile than men, which might impact on their 'marketability' (real or perceived), restricting the chances of external promotion in the absence of internal promotion. Geographical distance and the need to travel are specifically identified as barriers to women's progression within a regional Australian university (Thomas et al., 2019). Lipton (2015) observes that, for a variety of reasons, the rates of publication of females are typically lower than for males, especially in higher-ranked journals. She argues that performance measurement (within ERA) with a focus on metrics based on publications and grant income results in a gendered bias and is likely to impact negatively on women's academic career trajectories. Notwithstanding the progress in 
workplace practices and policies, White (2003) argues that senior academic women 'continue to experience both direct and indirect discrimination' within a 'hostile work environment'; she suggests that diversity management programmes have the potential to change the predominantly male-oriented management culture.

Several recent (international) studies identify that women tend to spend more time on teaching and service than men and less time on research (Coate and Howson, 2016; Guarino and Borden, 2017; Angervall and Beach, 2018, 2020). Student pastoral care may also 'fall' disproportionately on women (Brabazon and Schulz, 2018). These factors can lead to perceptions of women as 'worker bees' (Coate and Howson, 2016) or 'the housewives of academia' (Angervall and Beach, 2018). Such gendered differences in workload balance have the potential to influence career success (including promotion). In their consideration of policy changes to counteract barriers facing women in STEM disciplines, Greider et al. (2019) argue that promotion and similar evaluations should be conducted holistically and should not rely on 'false or superficial markers of career success' (such as high-quality publications). Inter alia, they suggest that women's greater focus on teaching and institutional service should be compensated to ensure fair treatment of women. They highlight a successful approach in mitigating such time pressures at Stanford University School of Medicine, via the development of a 'time-banking' program in which extra professional and personal support was provided to reward time spent teaching and in other team success activities (Fassiotto et al., 2018).

\section{Research questions}

The initial question concerns the level and quality of research outputs 'required' to obtain promotion to full professor in Australia. This is addressed by summarising the portfolios of published journal articles, as well as certain demographic characteristics relating to age and experience, at the time of promotion. The second objective is to investigate a range of factors suggested by prior literature that may potentially moderate promotion benchmarks; to facilitate comparisons this broadly follows the approach adopted in Beattie and Goodacre (2012). Finally, to further explore the international dimension of promotion requirements, a comparison is made between promotion portfolio expectations in Australia and prior published results for both the US and the UK. Each of the potential moderating variables is now considered in turn.

\subsection{Time}

The past 40 years have seen major changes in the Australian academic environment. These include the massification and corporatisation of higher education, relative declines in public funding, significant rises in part-time and casual appointments and major increases in student:staff ratios (Parker, 2011; 
Welch, 2012). Related changes include the internationalisation of universities, associated with the need to generate income in unregulated markets via full-feepaying international students, especially in the vocationally attractive subject areas of accounting and finance (Guthrie and Parker, 2014). Such developments potentially reduce the amount of time academics have for research, while increasing the importance of reputation-enhancing research, felt to be significant in marketing the university 'product'. Government concerns about 'value for money' and its desire for control, reflected in research assessment processes, have increased the pressure to publish and especially in designated top journals (ERA, 2018). The joint effect of these forces is a shortage of accounting and finance staff seemingly capable of producing research of appropriate quality (Welch, 2012). However, there has also been an increase in the number of academic accounting and finance journals and space within journals (Chan et al., 2012; Glover et al., 2012). ${ }^{4}$

Prior studies suggest that promotion publication requirements have increased over time (Beattie and Goodacre, 2012; Glover et al., 2012) but it is not clear, $a$ priori, whether this result will obtain in Australia. Requirements may have reduced as universities compete for the scarce resource of high-quality research faculty, or potentially increased in response to government and other pressures for improvements in research 'performance'. Research question 1 addresses this issue:

RQ1: Have the number and quality of research papers required for promotion to full professor and the related promotion demographics changed over time?

\subsection{Research intensity}

Promotion publication expectations appear to vary with the research intensity of the promoting university in the US (Fishe, 1998; Glover et al., 2006, 2012) but, somewhat surprisingly, not in the UK (Beattie and Goodacre, 2012). Prior studies that rank Australian accounting and finance 'departments' typically find that the traditional 'Group of 8' universities dominate the others (Chan et al., 2012; ERA, 2018). This leads to the second research question:

RQ2: Do the number and quality of research papers required for promotion to full professor and the related promotion demographics differ across university research intensity?

\footnotetext{
${ }^{4}$ Measured across all disciplines (including science, etc.), the number of refereed academic journals is estimated to have grown by about 4 percent per annum, on average, in both the recent past and over a very long period. The number of articles per journal has also increased. Article length varies substantially across disciplines and is second longest in the Social Sciences, on average (Tenopir and King, 2014).
}

(C) 2020 The Authors. Accounting \& Finance published by John Wiley \& Sons Australia, Ltd on behalf of Accounting and Finance Association of Australia and New Zealand 


\subsection{Discipline}

Prior US research suggests that the various disciplines within a business school context have significantly different publication norms and expectations (Swanson, 2004). Research question three considers whether such differences also occur between the accounting and finance sub-disciplines:

RQ3: Are the number and quality of research papers required for promotion to full professor and the related promotion demographics different for promotions within the separate accounting and finance areas?

\subsection{Core-discipline journals}

Prior (UK) evidence suggests that accounting and finance academics publish in a wide range of journals with just over half (54 percent) of the academic papers appearing within core accounting and finance journals and a further 10 percent in economics (Beattie and Goodacre, 2004). Further, promotion panels often include non-core academics in the decision-making process. In light of this, it is of potential continuing concern that business academics have 'limited knowledge of journals outside their speciality' (Henderson et al., 1990). It is, therefore, interesting to consider whether the location of outputs (within corediscipline journals or not) has any impact on promotion portfolio expectations. Any such impact is likely to depend on the relative influence of core-discipline academics in the promotion decision. Core-discipline decision makers may place greater weight on core-discipline publications so, for promotion portfolios including significant outputs in non-core journals, they may tend to expect a larger overall number of outputs to provide evidence of required scholarly ability. On the other hand, non-core decision makers may be neutral, or may even favour publications in (any) non-core journals that are more familiar to them. The relative importance of these arguments is difficult to establish a priori, so empirical evidence would be potentially useful. This leads to research question four:

RQ4: Does a focus on publishing in core-discipline journals affect the number and quality of research papers required for promotion to full professor?

\subsection{Gender}

It is important to consider the influence of gender in promotion decisions, especially as there is some evidence that female accounting academics perceived that it is more difficult for a woman to obtain promotion than an equally qualified man (Norgaard, 1989). Several studies have investigated empirically whether there are gender differences in research productivity of accounting academics, but with conflicting results. Some US studies found that males were 
more productive, but only at doctoral schools (Dwyer, 1994; Jordan et al., 2008), whereas others found no gender differences (Streuly and Maranto, 1994; Fogarty, 2004). Rama et al. (1997) considered papers published at the time of promotion to associate professor in the US; they found that females had significantly more publications than males, but only in non-doctoral schools. Outside the US, Beattie and Goodacre (2012) found no significant gender difference in pre-promotion portfolios but a cross-discipline study set in Canada showed that it took females longer than males to gain promotion (Stewart et al., 2009). The gender issue is considered in the fifth research question:

RQ5: Are the number and quality of research papers required for promotion to full professor and the related promotion demographics different for promotions achieved by male and female academics?

\subsection{Internal vs external promotion}

Chan (1996) analyses the choice between internal promotion and external appointment using an economic contest model framework. ${ }^{5}$ He suggests that opening up a post to external recruits can reduce internal staffs' work incentives. One way of maintaining incentives is to bias the selection process in favour of internal candidates. This strategy implies that an external appointee who overcomes this bias may have superior ability. However, the model also predicts that there may be a smaller effect at more senior levels where competition for a post is expected to be much lower. Chan's subsequent empirical evidence based on personnel data from a US financial institution is consistent with both of these predictions (Chan, 2006). Such favouring of internal candidates is unlikely to reflect the perception of many accounting and finance academic staff. Given the existence of more lucrative career opportunities, reduced competition is likely to pertain in the market for accounting and finance professors that, according to Chan's model, would also lessen any bias in favour of internal candidates. Further, internal promotions often involve cross-discipline comparison with academics from other disciplines, sometimes within the business areas, but also sometimes across an entire institution. These

\footnotetext{
${ }^{5}$ The Chan (1996) model compares internal and external candidates for an advertised position, whereas our academic research question seeks to compare separate internal and external (advertised) appointment processes. However, universities can choose to promote internally or advertise to seek an external appointment. Further, as we acknowledge, our set of internal appointees will no doubt include some who have been promoted internally to retain their services in light of an offer from another university's external appointment process. In light of these observations, we believe the insights from Chan's model are pertinent to our research question.
}

(C) 2020 The Authors. Accounting \& Finance published by John Wiley \& Sons Australia, Ltd on behalf of Accounting and Finance Association of Australia and New Zealand 
other disciplines often have higher publishing norms (Swanson, 2004) and higher research grant income, thereby increasing the competition for internal promotions. The net effect of such diverse influences on promotion is explored in the sixth research question:

RQ6: Are the number and quality of research papers required for promotion to full professor and the related promotion demographics different for internal and external promotions?

Additionally, it is worth noting that potential promotion candidates sometimes engage in gaming, by using an offer of external promotion to lever an internal promotion. This situation is unobservable to outsiders to the negotiations, so promotions classified in the current study as internal will be a mix of those resulting from internal competition and those externally levered. To the extent that 'genuine' internal promotees are required to demonstrate differential competence, any such gaming will bias against finding a significant difference between internal and external output expectations.

\subsection{Co-authorship}

While co-authorship has the potential to increase research productivity and/ or improve quality, ${ }^{6}$ the time involved in 'negotiating' with co-authors may also slow down the research process (Tucker et al., 2016). Further, co-authorship is likely to be less useful in some research designs. Some prior research has suggested that co-authored papers may be given less than full 'weight' and that sole-authored papers may be important in establishing independent research ability (Schinski et al., 1998). If this is true then promotees with fewer soleauthored outputs may require a larger overall number of papers to compensate, implying a negative relationship between the two. Research question seven considers the co-authorship issue:

RQ7: Does engaging with other academics via paper co-authorship affect the number and quality of research papers required for promotion to full professor?

\subsection{International comparisons}

Potts (2014) provides a description of academic migration to Australia and notes the major 'brain gain' from overseas, in particular from the UK and the

\footnotetext{
${ }^{6}$ For accounting, Endenich and Trapp (2016) provide evidence that co-authorship increases an author's total number of publications but not the weighted number (i.e., allowing for fractional involvement). Further they find no evidence that co-authorship improves impact (proxied by citations).
}

(C) 2020 The Authors. Accounting \& Finance published by John Wiley \& Sons Australia, Ltd on behalf of Accounting and Finance Association of Australia and New Zealand 
US; however, the relative proximity to Asia adds a further dimension. In light of Australia's demographic history and increased globalisation, the relative influence of 'local' and 'global' factors on promotion is worthy of investigation. In particular, promotion portfolio characteristics can be compared with prior published results for the US and the UK to enable consideration of research question eight:

RQ8: To what extent are the number and quality of research papers required for promotion to full professor influenced by 'local' and 'global' factors?

Comparison of the impact of university research intensity on promotion expectations with prior US and UK studies will also enable further consideration of the relative importance of institution and discipline in influencing academic identity (Beattie and Goodacre, 2012).

\section{Methods}

\subsection{Data collection}

The population of academic staff promoted to full professor (level E) in both accounting and finance disciplines was identified via university web pages. It is possible to extract publication and demographic data from various sources including individuals' university web pages, supplemented and checked using Scopus, Google Scholar and other sources. However, information such as dates (and locations) of $\mathrm{PhD}$ and promotions, and 'years as an academic/age' are not always publicly available, so an email request for such information was sent to each individual academic after obtaining ethics approval for the project and gatekeeper approval to contact individual academics. Eight gatekeepers refused access. A follow-up email was sent after a suitable delay in instances of non-response.

Initial analysis of the data suggested differences between accounting and finance sub-groups. This, coupled with concerns about non-response bias, necessitated the adoption of a search for non-respondents' data from online sources. This was successful in achieving a high level of coverage of the sampling frame together with a good level of data reliability and completeness (see Table 1 in Section 5 below).

\subsection{Proxy for journal quality}

The quality of an academic's research is viewed as a major factor in career advancement, but is not directly observable. This means that a proxy is required for the quality of publications. Journal rankings typically seek to fill this role and are usually based on either citation analysis or perception surveys; both suffer from limitations, albeit different ones. Recent promotion studies have used journal ranking lists considered most relevant to their national environment. The two US studies (Glover et al., 2006, 2012) relied on the survey results of Barniv 
and Fetyko (2001) and the 'most recent' Financial Times Business School Journal Ranking and focused on just 60 top accounting and business journals, with a catch-all category for 'all other' peer-reviewed publications. The UK study (Beattie and Goodacre, 2012) used the Association of Business Schools Journal Quality Guide (Harvey et al., 2008), which has a much broader coverage of 1,025 business journals, including 125 'Accounting and Finance' journals.

For the current study, a similarly broad listing of specific relevance to the local environment produced by the Australian Business Deans Council (ABDC, 2013) was adopted. This list was reviewed and updated in 2013 using a series of discipline expert panels, following an open consultation process taking account of interested parties' feedback and commentary. ${ }^{7}$ It lists 2,769 journals including 127 in 'Accounting, auditing and accountability (Field of Research (FoR) 1501), 180 in 'Banking, finance and investment' (FoR 1502) and 671 across the four Economics sub-groups (FoR 14, split across 'Economic Theory' (1401), 'Applied Economics' (1402), 'Econometrics' (1403) and 'Other Economics' (1499)). The ABDC Journal Quality list 2013 is divided into four categories designated, in declining levels of quality, as $\mathrm{A}^{*}, \mathrm{~A}, \mathrm{~B}, \mathrm{C}$. In the highest $A *$ category, there are 9 (FoR 1501), 11 (FoR 1502) and 46 (FoR 14) journals. Overall, of the 978 relevant discipline journals in these FoRs, there are 7 percent (A*), 16 percent (A), 29 percent (B) and 45 percent (C), respectively.

Output measures used in the present study include the total number of publications, the number within each of the ABDC quality categories and across the full ABDC list, as well as in journals 'not classified' within the ABDC list. ${ }^{8}$ To simplify results presentation, an author is given full credit for a paper if listed as one of the authors; anecdotal and research evidence suggests this often applies in practice (Nathan et al., 1998). ${ }^{9}$ The number of $\mathrm{A}^{*}$ level, A

\footnotetext{
${ }^{7}$ Following a similar list revision process, an updated journal list was published on 6 December 2019 (ABDC, 2019). The 2019 list endorses 2,682 journal entries with the following overall classifications: A* 7.4 percent; A 24.3 percent; B 31.7 percent; C 36.6 percent. The changes included 144 upgrades; 17 downgrades; the addition of 157 new journals; and the removal of 241 journals. In the highest $A^{*}$ category, there are now 13 'accounting' (FoR 1501), 13 'finance' (FoR 1502) and 49 'economics' (FoR 14) journals. Overall, of the 1,003 relevant discipline journals in these FoRs, there are now 7.5 percent (A*), 18.2 percent (A), 31.5 percent (B) and 42.9 percent (C), respectively. While the increased number of $A^{*}$ category journals will no doubt be welcomed by accounting and finance researchers, the overall story is one of broadly stable categorisations.

${ }^{8}$ The categorisation as 'Not classified' does not necessarily imply that these publications are in journals of inferior quality. Whilst it might imply an inferior quality journal, it could also mean that the journal is merely outside what ABDC has determined as 'Business and Management' disciplinary boundaries.

${ }^{9}$ However, an alternative measure, sometimes used in research productivity studies (Chan et al., 2012), gives only partial credit to an author based on the number of authors (n) on the paper (partial credit $=1 / n$ ). This measure was also explored, and results were reported in an earlier working paper version (Goodacre et al., 2017).
}

(C) 2020 The Authors. Accounting \& Finance published by John Wiley \& Sons Australia, Ltd on behalf of Accounting and Finance Association of Australia and New Zealand 
Table 1

Summary of professor promotion sampling and characteristics

\begin{tabular}{lllc}
\hline & Accounting & Finance & Total \\
\hline Professors per University websites & 102 & 82 & 184 \\
Non-relevant, non-Australian promotions or duplicates & $(5)$ & $(11)$ & $(16)$ \\
Sampling frame & 97 & 71 & 168 \\
Missing data & $(11)$ & $(7)$ & $(18)$ \\
Potential sample & 86 & 64 & 150 \\
Outliers & $(0)$ & $(3)$ & $(3)$ \\
Total usable sample & $\mathbf{8 6}$ & $\mathbf{6 1}$ & $\mathbf{1 4 7}$ \\
\% of sampling frame & 89 & 86 & 88 \\
& & & \\
Gender & Accounting & Finance & Total \\
Male & 61 & 52 & 113 \\
Female & 25 & 9 & 34 \\
Total & $\mathbf{8 6}$ & $\mathbf{6 1}$ & $\mathbf{1 4 7}$ \\
& $($ Chi-Square $=$ & $4.11(p=0.04))$ \\
Internal or External promotion & & & \\
Internal & Accounting & Finance & Total \\
External & 48 & 28 & 76 \\
Total & 38 & 33 & 71 \\
& $\mathbf{8 6}$ & $\mathbf{6 1}$ & $\mathbf{1 4 7}$ \\
Gender & $($ Chi-Square $=$ & $1.40(p=0.24))$ \\
Male & & & \\
Female & Internal & External & Total \\
Total & 56 & 57 & 113 \\
& 20 & 14 & 34 \\
University category (post-promotion) & $\mathbf{7 6}$ & $\mathbf{7 1}$ & $\mathbf{1 4 7}$ \\
go8 & $($ Chi-Square $=0.90(p=0.34))$ \\
60sn70s & & & \\
ATN & Accounting & Finance & Total \\
NewGen & 31 & 21 & 52 \\
Regional & 27 & 14 & 41 \\
Total & 15 & 16 & 31 \\
& 4 & 5 & 9 \\
& 9 & 5 & 14 \\
& $\mathbf{8 6}$ & $\mathbf{6 1}$ & $\mathbf{1 4 7}$ \\
& $($ Chi-Square $=$ & $3.17(p=0.53))$ \\
\hline
\end{tabular}

level and the sum of these ('A*+A' level) are used as indicators of higher quality publications.

An alternative proxy is also adopted based on the number of papers published in journals indexed in the Social Science Citation Index and the Science Citation Index, which we term 'Web of Science' papers. This measure forms part of the Academic Ranking of World Universities (ARWU) published annually since 2003 by Shanghai Jiao Tong University and contributes 20 percent to the overall ranking score (Shanghai Jiao Tong University, 2016); the ARWU ranking is used by some Australian universities and government 
agencies to benchmark performance (ACIL Allen Consulting, 2013; La Trobe University, 2016; University of Newcastle, 2016).

\subsection{Proxy for university 'research intensity'}

Prior US research typically finds that publication quality expectations for promotion in both accounting and finance are positively associated with the research intensity of the promoting university (Fishe, 1998; Glover et al., 2006, 2012). To enable investigation of this issue in the present study, a proxy is required for research intensity that is relevant to the Australian context. The classification of universities by Moodie (2012), which updates the prior Marginson (1997) classification, has been adopted in the present study. This grouping uses the terms: 'Group of 8'; '1960s-1970s'; 'ATN-like'; 'New generation'; and Regional'. ${ }^{10}$ However, the small sample sizes observed here for the latter two groups necessitated their combination into a single 'New generation/Regional' group for the purpose of analysis. Given the long time period of analysis in the present study, the reasonableness of this proxy requires the further assumption that research intensity remains relatively stable over time. The consistency between Marginson (1997) and Moodie (2012) suggests that such an assumption has some credibility.

\section{Results}

\subsection{Sample descriptives and overall results}

Table 1 summarises the number of responses obtained directly from staff and those for whom sufficient and reliable information could be found online. Overall, the approach provided a total usable sample of 147 promotions to full professor (86 accounting, 61 finance) at Australian universities, representing 88 percent of the sampling frame; these promotions took place during a total period of 37 years (1978-2014). ${ }^{11}$ Consistent with prior studies of gender

\footnotetext{
${ }^{10} \mathrm{~A}$ full listing of group constituents is provided in Appendix 1 of the earlier working paper version (Goodacre et al., 2017). An alternative proxy, based on results from the government-based Excellence in Research for Australia (ERA), was also adopted in that version; almost identical results were obtained, so ERA-based results are not presented here to simplify presentation.

${ }^{11}$ Three finance professors, all promoted to ' 60 sn 70 s' universities, had unusually high levels of total outputs $(113,98$ and 79) and are considered outliers. These output levels are respectively 6.0, 4.9 and 3.6 times the interquartile range above the upper quartile so, to avoid distortions, the promotions have been removed from the sample. However, to check robustness, the multivariate regressions were also run including the outliers. A small number of differences in significance were noted, specifically concerning university research intensity, promotee experience and time. Apart from these, there were just minor changes in coefficient sizes and occasionally in significance suggesting that the overall conclusions are robust.
}

(C) 2020 The Authors. Accounting \& Finance published by John Wiley \& Sons Australia, Ltd on behalf of Accounting and Finance Association of Australia and New Zealand 
balance in senior positions within organisations, only 34 ( 23 percent) of the overall number are female. There are more female promotees in accounting (25, representing 29 percent) than in the finance discipline ( 9 , representing just 15 percent); the association between gender and discipline is statistically significant (chi-squared $=4.11 ; p=0.04$ ). Roughly half of the overall promotions were internal, and half were external first-time professorial appointments. A slightly larger proportion of promotions were internal for females (59 percent) than for males (50 percent), consistent with prior Australian evidence on women's lower mobility (Kahn, 2012). The number of promotions at 'New generation' and 'Regional' universities was relatively small (23), representing just 16 percent of the sample. The associations in the last three cross-tabulations of Table 1 are all non-significant, based on chi-squared tests.

An overall summary of the publication profiles and age/experience demographics for the full sample is provided in Panel A of Table 2. At the time of promotion, professors had published a mean (median) of 17.0 (15.0) papers in ABDC-listed journals, with a total of 8.2 (7) at the highest A*/A quality levels. Of the total, 3.9 (3) would be sole-authored papers, together with a range of coauthored papers leading to an average total of 2.2 authors per paper. On average, 9.1 (8) papers had been published in journals indexed in Web of Science. These averages hide a wide variation across promotees. The total number of publications at the time of promotion varied between 3 and 50 , including $0-13(0-20)$ publications in journals categorised as $A^{*}(A)$ in the ABDC list.

Detailed analysis of the data confirms that pre-promotion publication in the highest quality journals (proxied by $\mathrm{A}^{*}$ classification in the ABDC list) is challenging. Of the total 2,506 papers across the full promotion set, just 286 (11.4 percent) were published in $\mathrm{A}^{*}$ journals; further, 53 of the 147 promotees (36 percent) had no publications in $A^{*}$ journals at the time of promotion.

The mean (median) age of promotees was 44.8 (44) years and they had 14.9 (14) years' academic experience in a research-inclusive role. There was a wide age range, with the youngest promotion to professor at 30 years old and the oldest at 64. A wide range of pre-promotion academic experience is also observed. While the average number of years post-PhD was 9 , the distribution ranged from obtaining a $\mathrm{PhD} 7$ years after promotion (post- $\mathrm{PhD}=-7$ ) to obtaining one 25 years prior to promotion. A small number of professors (5) did not have a PhD.

\subsection{Bivariate analysis}

Panel B of Table 2 addresses RQ1 by providing a time-based analysis of differences in the measures with summaries provided for the periods 1978-1998, 1999-2008 and 2009-2014. These time ranges have been chosen to reflect changes in the university environment and to achieve a reasonable sample split across the three periods. The early period spans the elimination of the binary

(C) 2020 The Authors. Accounting \& Finance published by John Wiley \& Sons Australia, Ltd on behalf of Accounting and Finance Association of Australia and New Zealand 


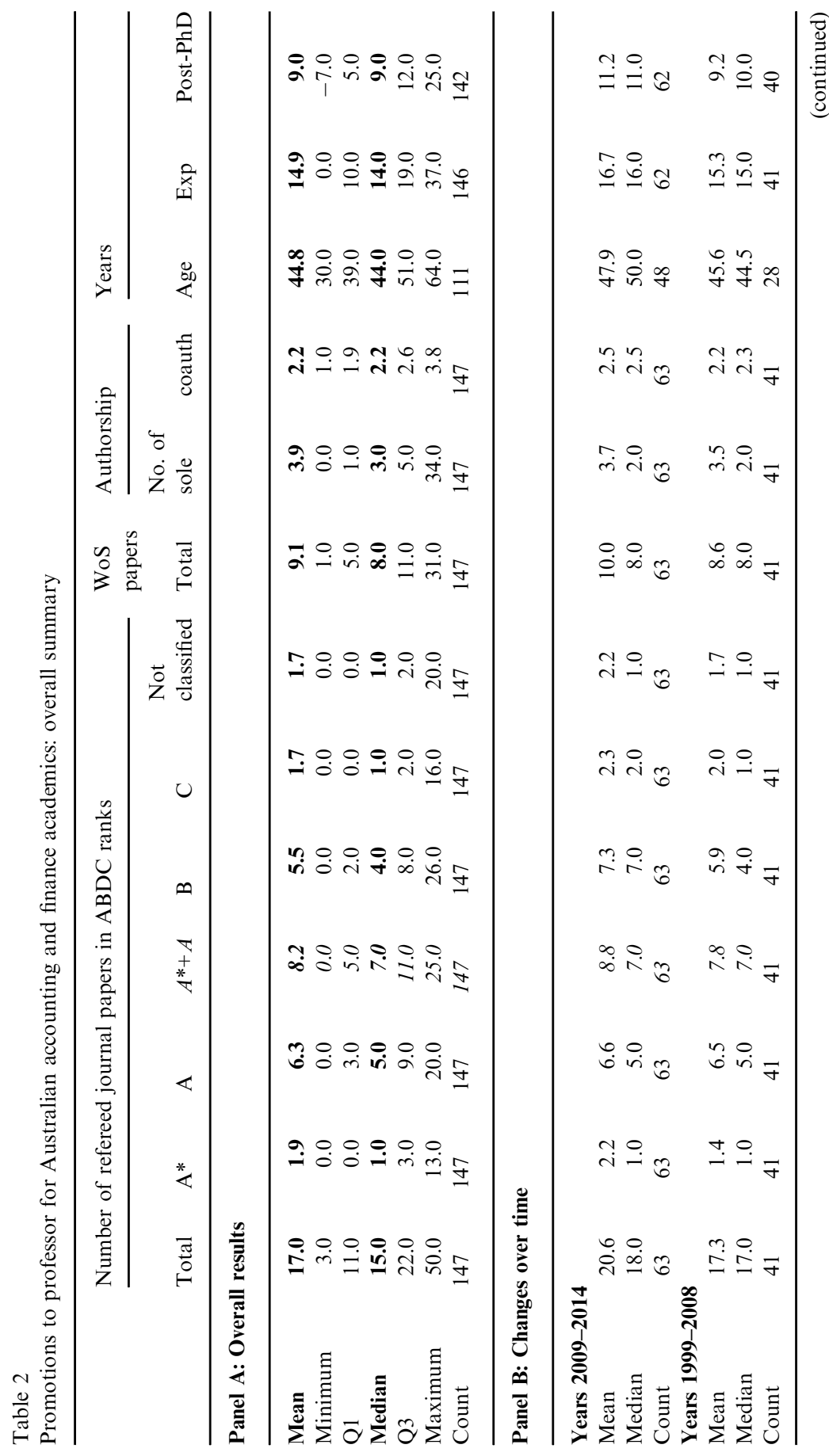

(C) 2020 The Authors. Accounting \& Finance published by John Wiley \& Sons Australia, Ltd on behalf of Accounting and Finance Association of Australia and New Zealand 


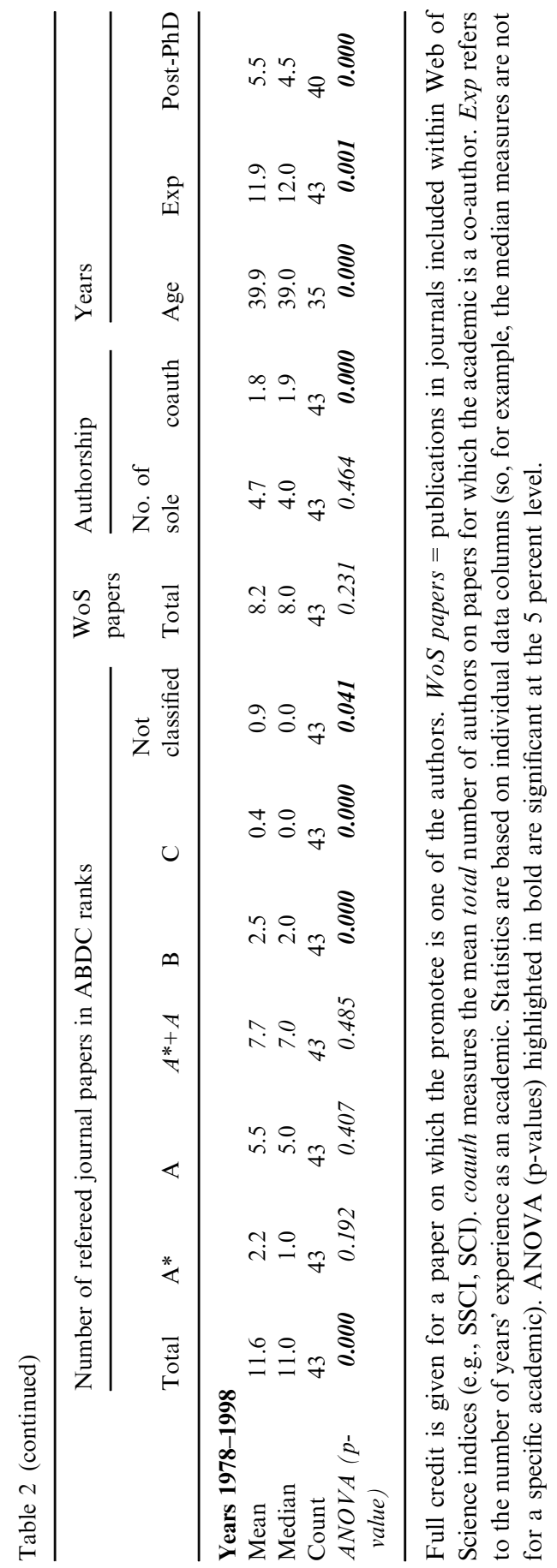

(C) 2020 The Authors. Accounting \& Finance published by John Wiley \& Sons Australia, Ltd on behalf of Accounting and Finance Association of Australia and New Zealand 
divide (in 1988); the middle period covers the introduction of the Research Quality Framework (RQF) in 2004, with its greater emphasis on quantity rather than quality; the late period reflects the ERA regime. Further, results for the late period provide a more up-to-date summary of current expectations of research portfolios required for promotion.

The results in Panel B demonstrate a significant increase in the total number of pre-promotion publications over time, but the increase occurs mainly in lower level journals rather than $\mathrm{A}^{*}$ and A journals. Co-authorship seems to have increased over time, and promotions appear to be achieved later in careers: promotees are older, have more experience and more post-PhD years, on average. All of these results are also confirmed by significant positive correlations (Pearson) between each measure and year of promotion. Overall, these time change results broadly mirror those found in the later US study (Glover et al., 2012).

Table 3 provides an initial bivariate assessment of RQ2. It reports an analysis of the mean numbers of publications in promotion portfolios across the different university groupings, but with the 'New generation' and 'Regional' small samples combined. Summaries are provided across all years, and then for the most recent 2009-2014 period, to facilitate benchmarking. The means for the total number of publications do not differ significantly across the university groups (based on an ANOVA test, $p$-values at the foot of the table). This is perhaps surprising given prior evidence of significant inter-group differences, generally, in the mean numbers of refereed publications (Subramaniam, 2003).

However, there are significant differences in the means for the number of higher quality ABDC-level journal outputs, both recently and across all years. The differences are strongly statistically significant for $\mathrm{A}^{*}$-level and combined ' $A *+A^{*}$, but not for A-level journal outputs. For quality journals, the ordering of university groupings is 'Group of 8' > 'Australian Technology Network' > '1960s-1970s' > 'New generation/Regional'. This suggests that more researchintensive universities have greater expectations of higher quality journal outputs for appointment, or promotion, to full professor. Similar observations can be made in relation to Web of Science outputs. In contrast, Beattie and Goodacre (2012) found that quality expectations in the UK did not differ greatly across the range of university research intensities. They argued that this was consistent with the accounting and finance disciplines retaining a significant influence over promotion expectations, lending support to the contention that disciplines continued to be important in framing academics' identity. However, the contrasting results for Australia imply that institutions have greater influence over promotion norms, consistent with the views expressed by university managers in Marginson and Considine (2000). In turn, this suggests that institutions may be more influential in the framing of academic identity.

The smaller number of lower-ranked outputs in 'Group of 8' portfolios is suggestive of quantity substituting for quality in the other university groupings. 


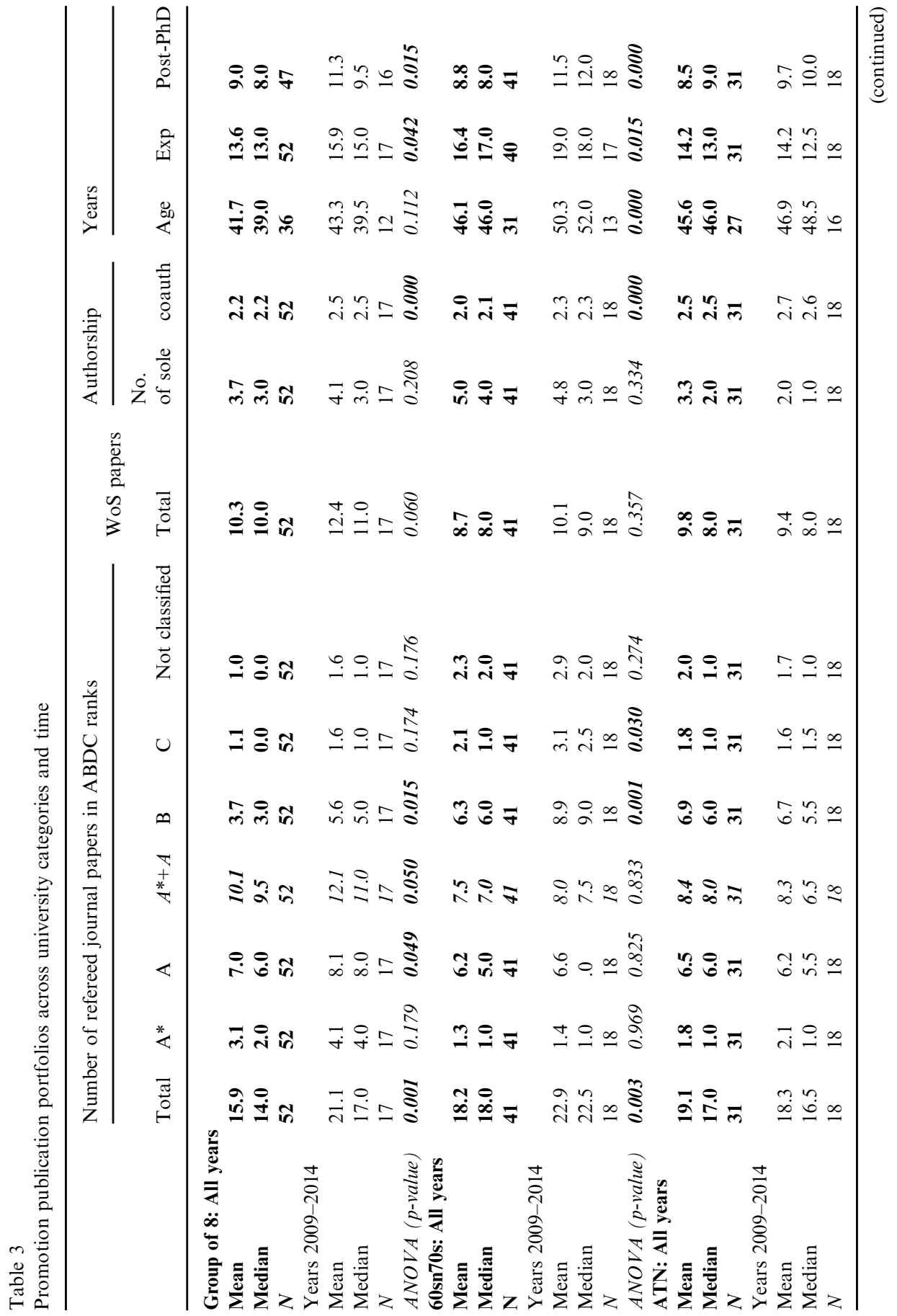

(C) 2020 The Authors. Accounting \& Finance published by John Wiley \& Sons Australia, Ltd on behalf of Accounting and Finance Association of Australia and New Zealand 


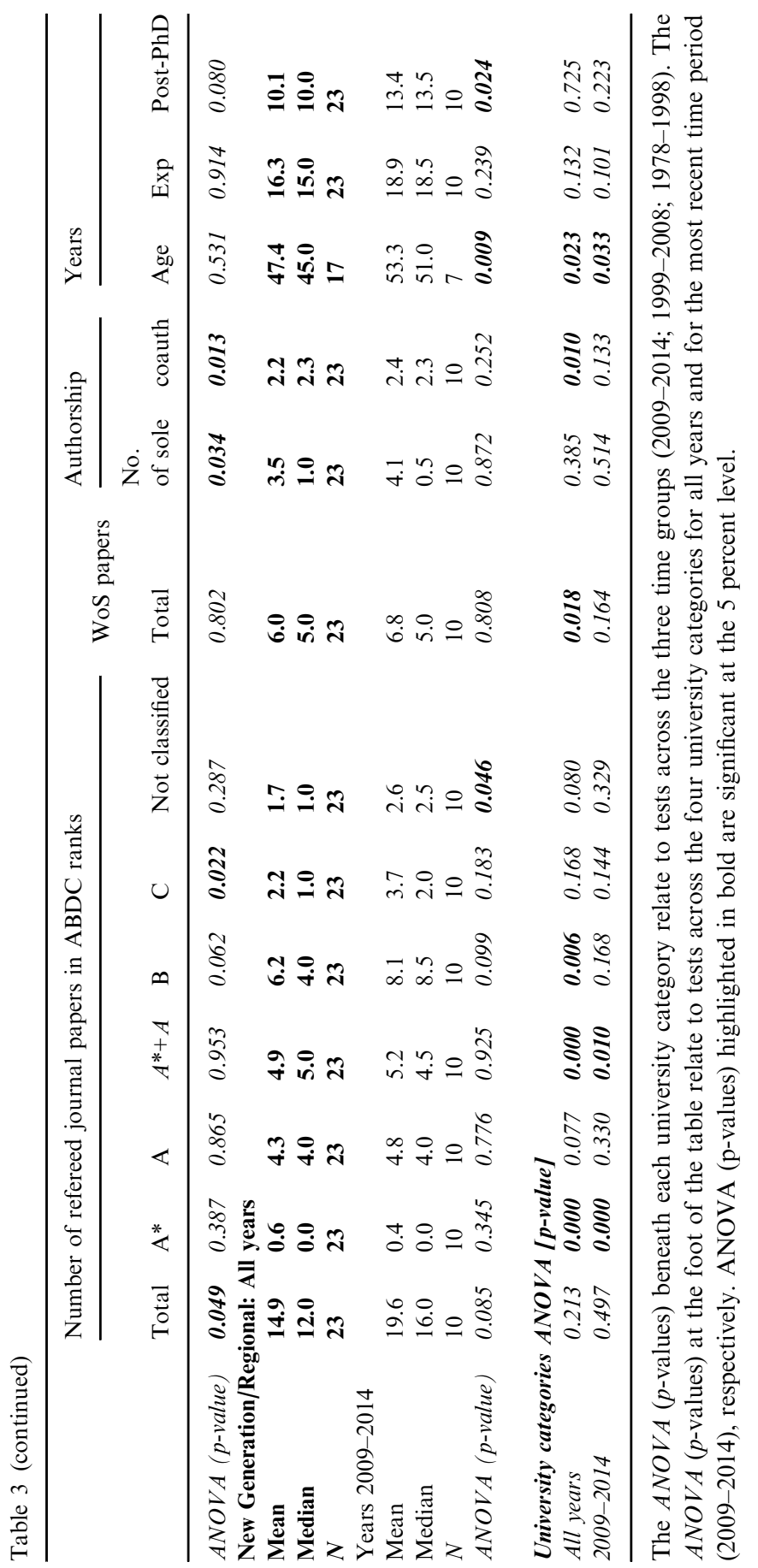

(C) 2020 The Authors. Accounting \& Finance published by John Wiley \& Sons Australia, Ltd on behalf of Accounting and Finance Association of Australia and New Zealand 


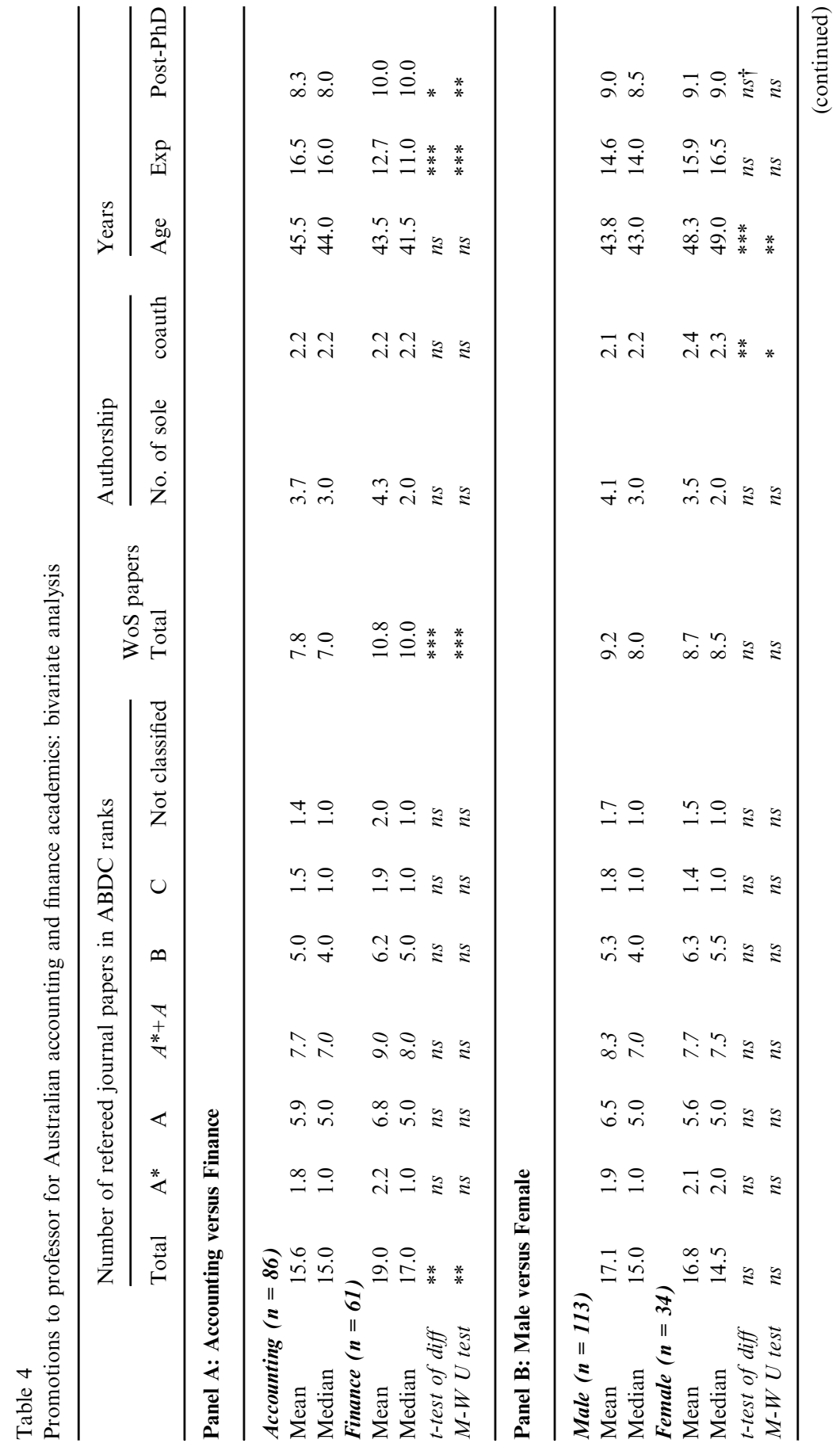

(C) 2020 The Authors. Accounting \& Finance published by John Wiley \& Sons Australia, Ltd on behalf of Accounting and Finance Association of Australia and New Zealand 


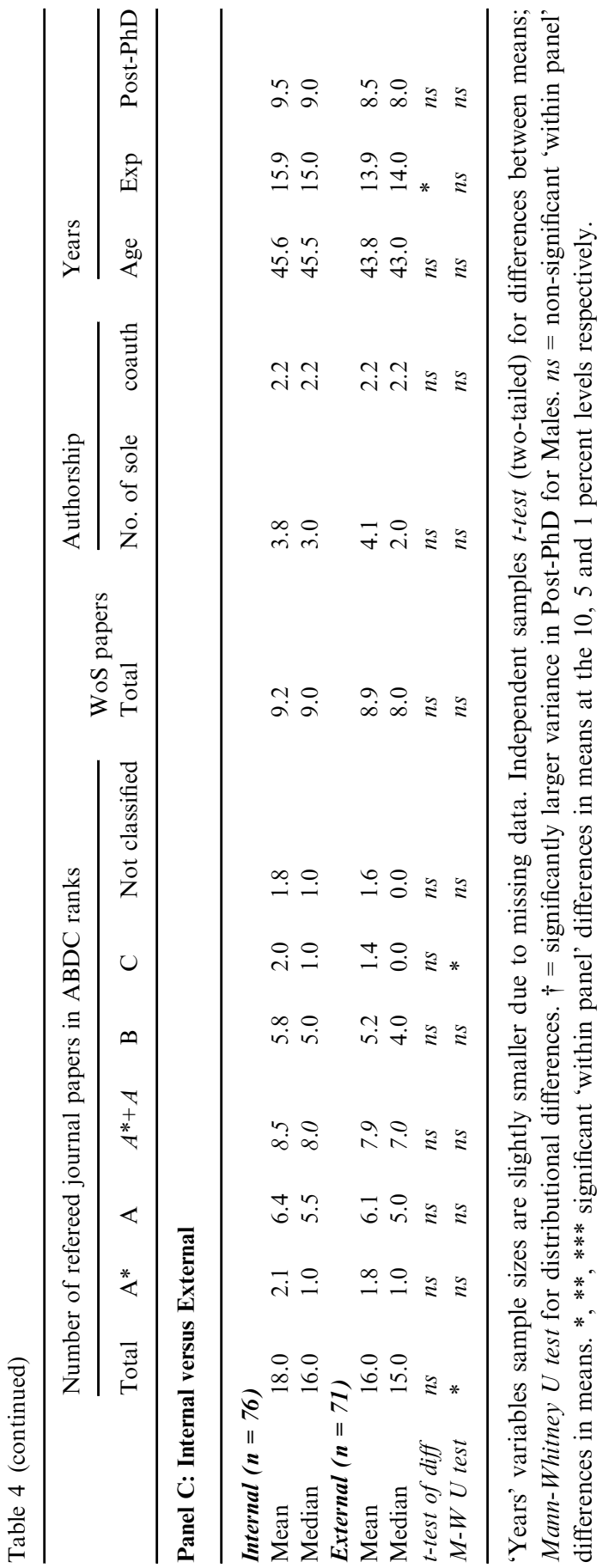

(C) 2020 The Authors. Accounting \& Finance published by John Wiley \& Sons Australia, Ltd on behalf of Accounting and Finance Association of Australia and New Zealand 


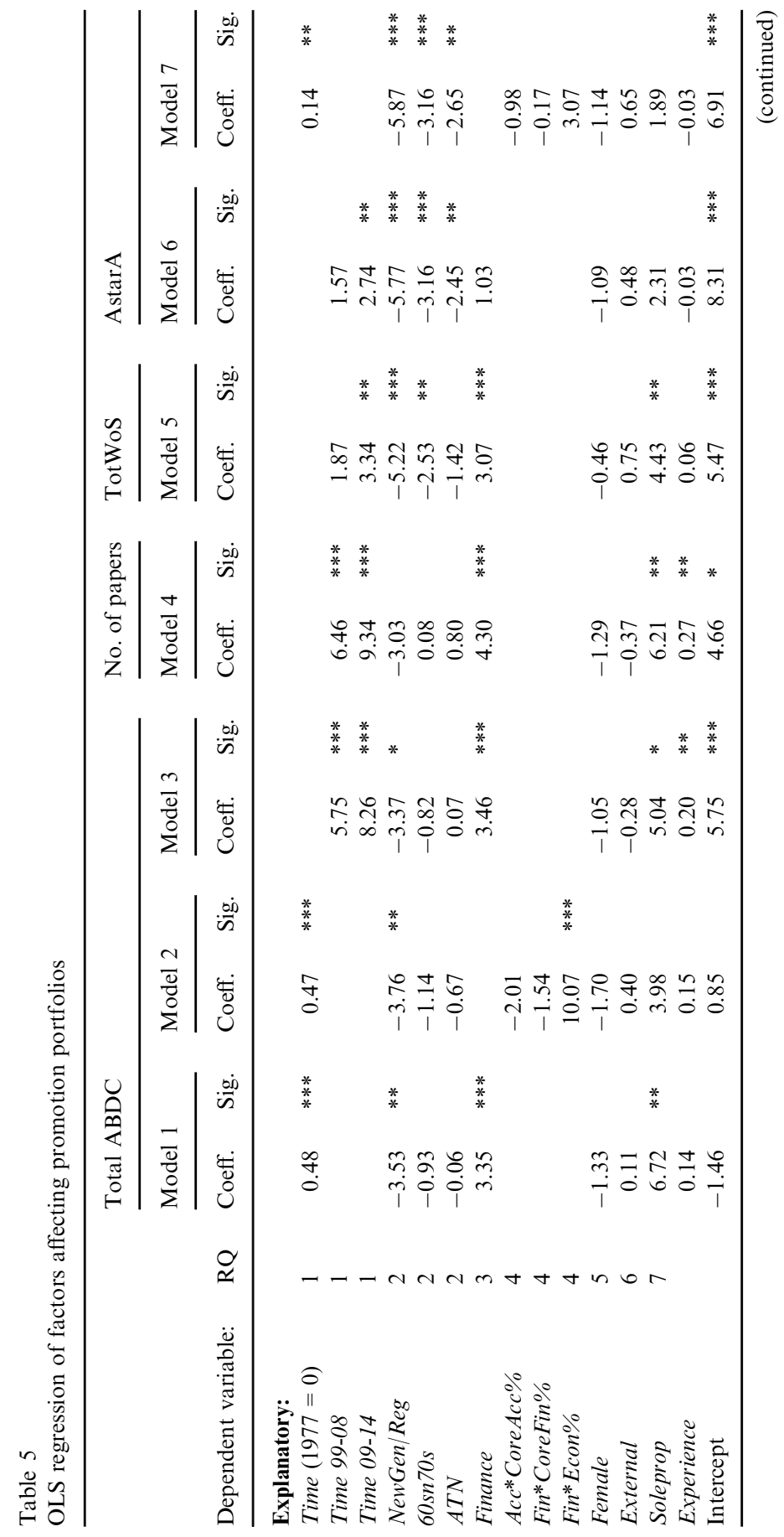

(C) 2020 The Authors. Accounting \& Finance published by John Wiley \& Sons Australia, Ltd on behalf of Accounting and Finance Association of Australia and New Zealand 


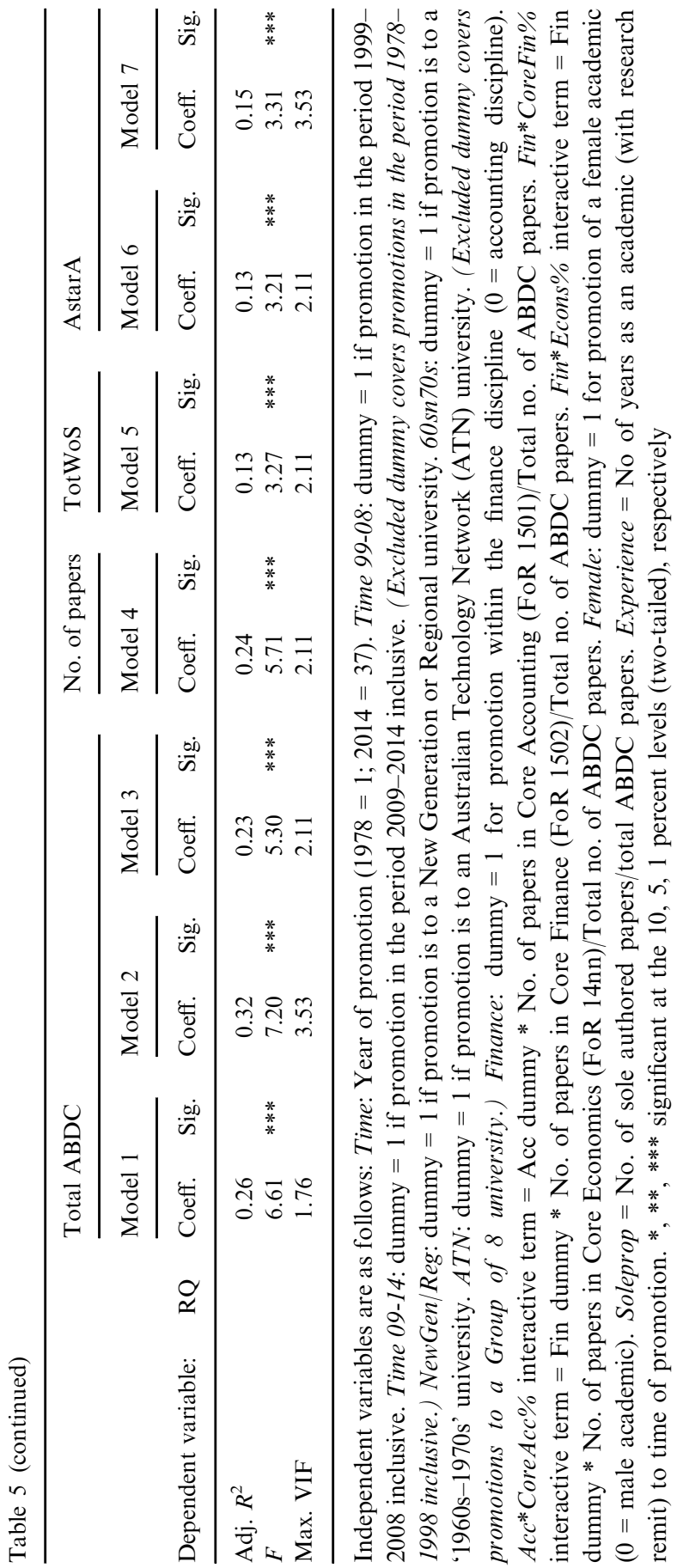

(C) 2020 The Authors. Accounting \& Finance published by John Wiley \& Sons Australia, Ltd on behalf of Accounting and Finance Association of Australia and New Zealand 


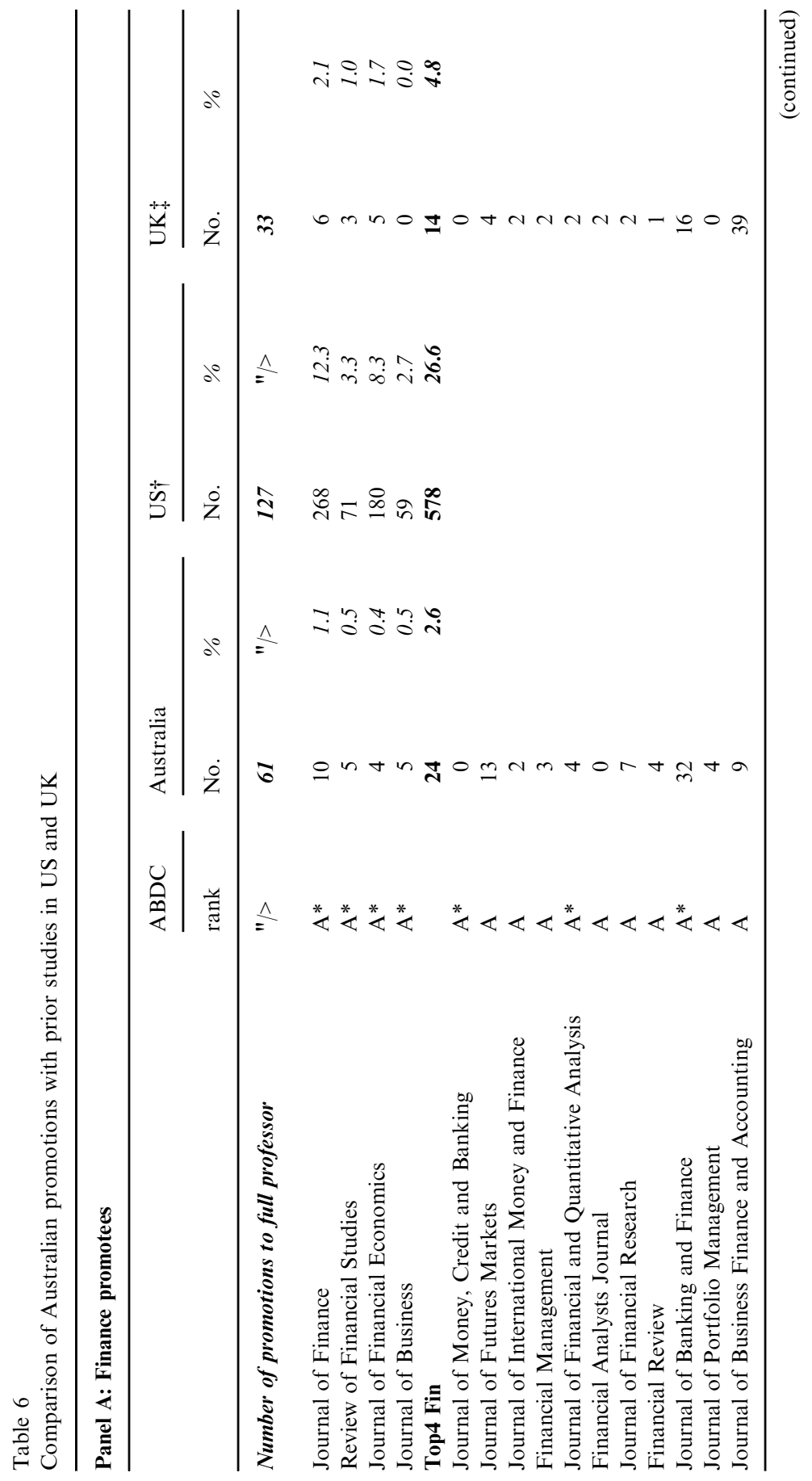

(C) 2020 The Authors. Accounting \& Finance published by John Wiley \& Sons Australia, Ltd on behalf of Accounting and Finance Association of Australia and New Zealand 


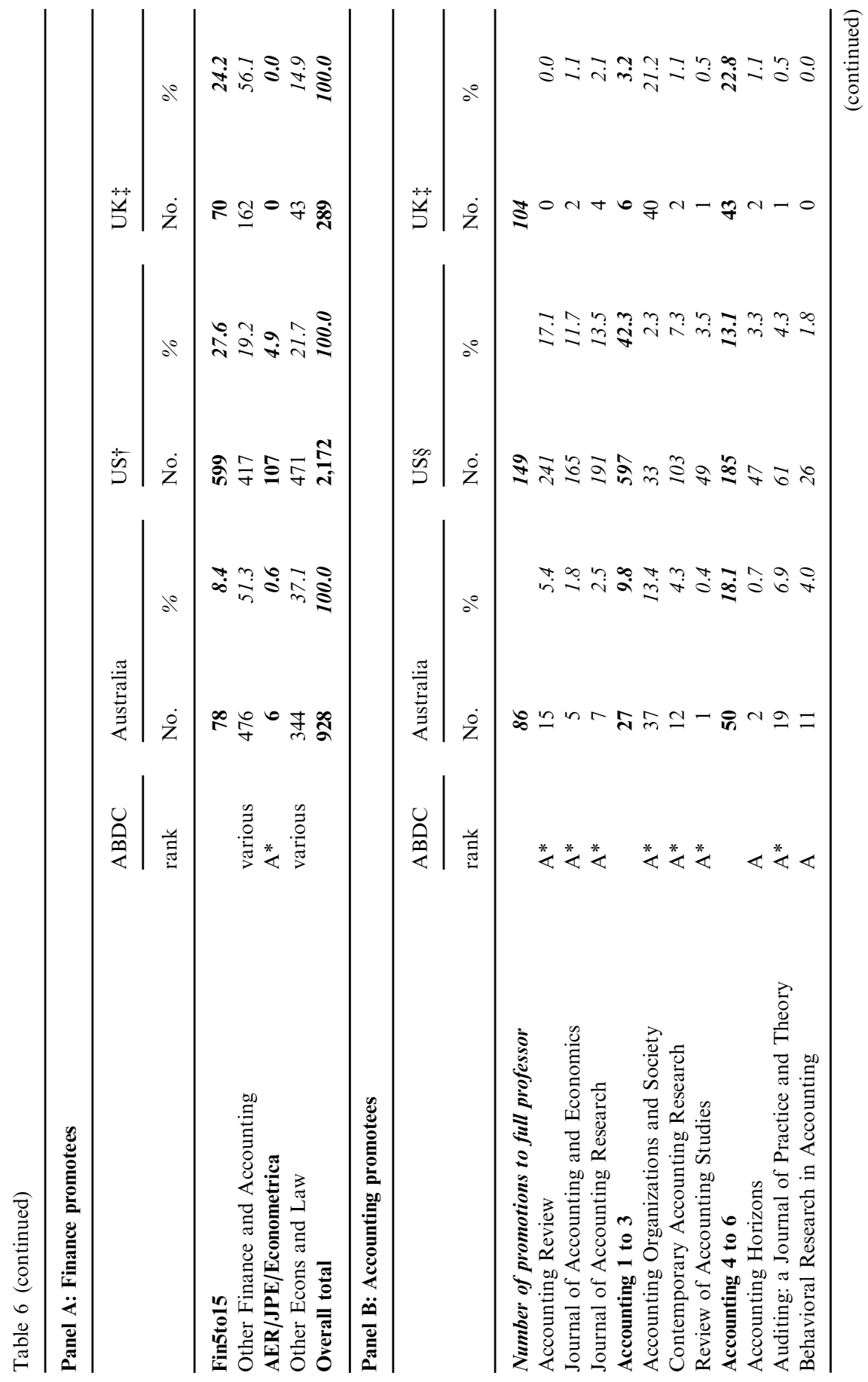

(C) 2020 The Authors. Accounting \& Finance published by John Wiley \& Sons Australia, Ltd on behalf of Accounting and Finance Association of Australia and New Zealand 


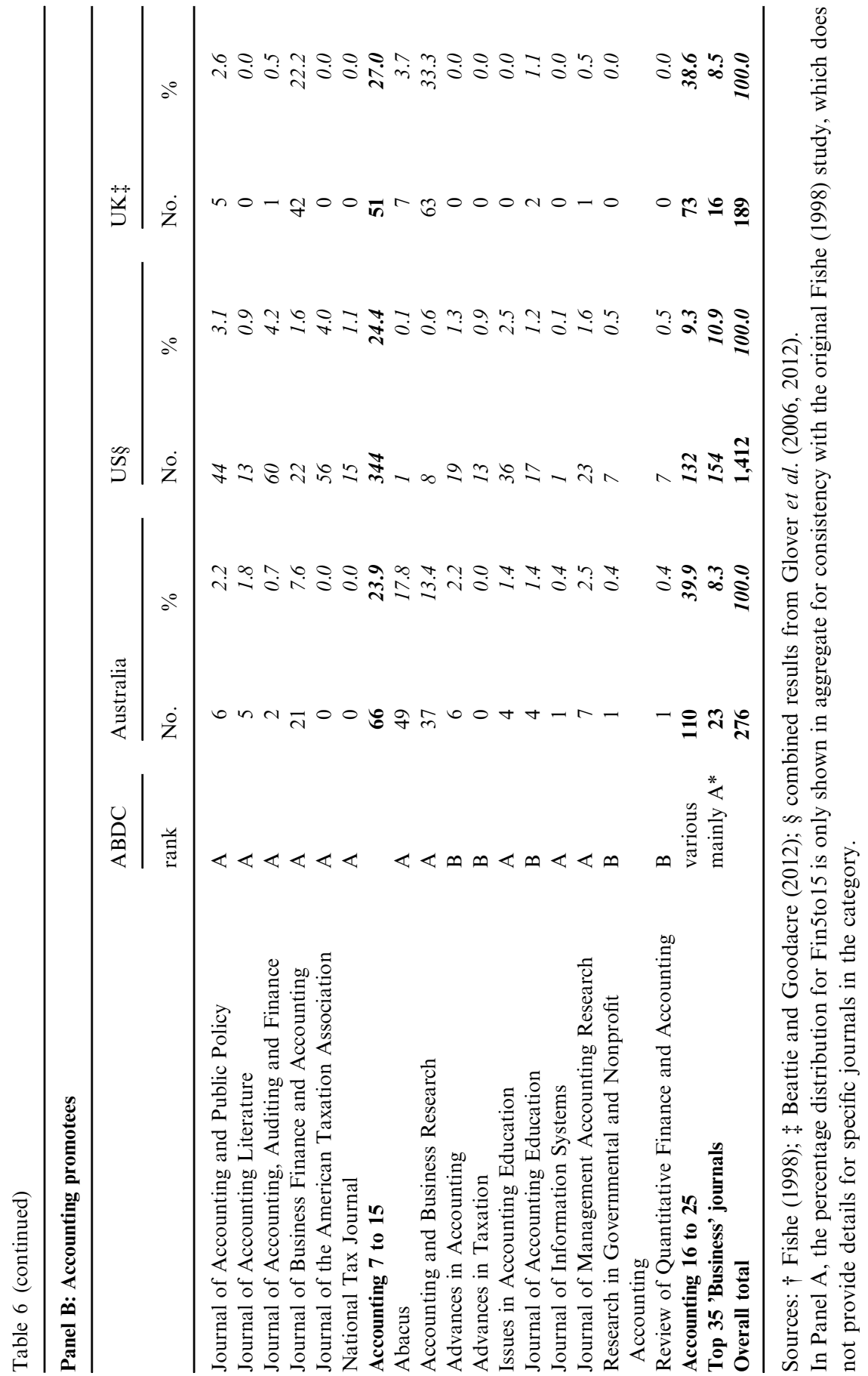

(C) 2020 The Authors. Accounting \& Finance published by John Wiley \& Sons Australia, Ltd on behalf of Accounting and Finance Association of Australia and New Zealand 
These substitution results are consistent with professorial promotions in the US (Fishe, 1998; Glover et al., 2006) but not in the UK (Beattie and Goodacre, 2012).

The time-based ANOVA analysis for each university group in Table 3 provides evidence of increased publication expectations over time, mainly in lower quality journals. However, both A-level and combined 'A*+A'-level requirements have also increased, but only at 'Group of 8' universities. Table 3 also shows that full professor status is typically achieved at a younger age in 'Group of 8' universities. Finally, there is evidence that promotees now have to wait longer to achieve promotion than in earlier periods of the sampling frame; i.e., age, experience and post- $\mathrm{PhD}$ years have typically increased over the time frame.

Initial bivariate analysis by discipline (accounting compared with finance) (RQ3), gender (RQ5) and by internal/external promotion (RQ6) is summarised in Table 4.

Panel A considers whether there are any discipline-related differences in promotion expectations and attributes. Here, finance professors had significantly more publications $($ mean $=19.0)$ at the time of promotion than accounting professors $($ mean $=15.6)$. Finance promotees also had significantly more publications in Web of Science indexed journals (mean $=10.8$ compared with 7.8 for accounting). However, the challenge of publishing in high-quality (A*) journals seems to be broadly similar across both accounting and finance. Additional detailed analysis shows that for accounting (finance), 11.2 percent (11.6 percent) of promotion portfolios were in $\mathrm{A}^{*}$ journals, Further, a significant proportion of promotees had no $\mathrm{A}^{*}$ papers at all in their promotion portfolio: 38.4 percent of accounting and 32.8 percent of finance promotions.

There are some significant differences in the timing of promotions. Accounting promotees had greater academic experience (mean $=16.5$ years) than finance promotees (mean $=12.7$ years), but a shorter period post-PhD. These observations are consistent with a proportion of accounting academics entering academe after completion of a professional accounting qualification followed by $\mathrm{PhD}$ training while in an academic position (Cappelletto, 2010). By contrast, perhaps a larger proportion of finance staff completes a $\mathrm{PhD}$ immediately after their undergraduate degree and before obtaining their initial academic post. On average, this may lead to promotions at a younger age for finance staff, after fewer years of academic experience but with more years post$\mathrm{PhD}$.

Panel B considers gender issues. In particular, are there any differences between male and female promotees in terms of publications and/or demographics? The difference in the mean number of total publications for males (17.1) and females (16.8) is not statistically significant. However, female promotees were typically older (mean $=48.3$ years $)$ than males (mean $=43.8$ years) and had slightly more academic experience, though the latter difference is not statistically significant. While there was no evidence of a 
gender difference in the number of years between obtaining a $\mathrm{PhD}$ and promotion (post-PhD), this period is significantly more diverse in the male than in the female sample. Overall, these results imply that females started their career as an academic with a research role about 3 years later than males. This is consistent with the views of women interviewees in prior research that, in comparison with men, their academic progress seemed to be 'slowed down' by various factors (Pyke, 2013).

Panel $\mathrm{C}$ contrasts profiles of internal and external promotions. In line with perhaps many academics' perceptions, internal promotees typically had a larger portfolio of publications than those gaining external first-time promotion to professor; however, the difference (mean $=18.0$ for internal compared with 16.0 for external) was not statistically significant. A similar non-significant pattern is demonstrated for both age and post- $\mathrm{PhD}$ period. However, internal promotees did have a marginally significantly ( $p<10$ percent) longer experience in research-oriented academic posts than external first-time promotees.

Tests of differences in publication quality, proxied by the number of publications in journals categorised in ABDC (2013) as A*, A and their sum $\left(A+A^{*}\right)$, were also undertaken. However, no statistically significant differences were observed across accounting/finance promotees, gender or internal/ external sub-samples.

\subsection{Multivariate analysis}

While the summaries are useful for benchmarking, interpretation of bivariate results is challenging given the ceteris paribus assumption. Multivariate analysis results based on ordinary least squares (OLS) regressions are, therefore, provided in Table 5, based on four dependent variable proxies for prepromotion portfolio quality (and quantity):

Total number of papers in ABDC-listed journals (Total ABDC)

Total number of papers in refereed journals (No. of papers)

Total number of papers in Web of Science indexed journals (Tot WoS $)$

Total number of papers in $\mathrm{A}^{*}$ or A level journals (AstarA)

[models 1-3]

[model 4]

[model 5]

[models 6 and 7]

Explanatory variables include year/period of promotion, university researchintensity groupings, accounting/finance discipline, proportion of outputs in core journals, ${ }^{12}$ gender, internal/external promotion, and sole authorship (proportion of outputs). Given that the number of research outputs is likely to

\footnotetext{
${ }^{12}$ As expected, publications are focused within core research areas. For accounting promotees, 69.6 percent of their publications were in 'Accounting, Auditing and Accountability' (FoR 1501) journals. For finance promotees, a total of 42.3 percent was in 'Banking, Finance and Investment' (FoR 1502) with a further 33.1 percent in Economics (FoR 14), predominantly in 'Applied Economics' (FoR 1402: 27.7 percent).
}

(C) 2020 The Authors. Accounting \& Finance published by John Wiley \& Sons Australia, Ltd on behalf of Accounting and Finance Association of Australia and New Zealand 
increase with the number of years as a research-active academic, promotee experience is included as a control variable.

The models have acceptable explanatory power: adjusted $R^{2}$ ranges between 0.13 and 0.32 and $F$-statistics are all significant at the 1 percent level. Collinearity does not seem to be a major issue, given the overall maximum VIF level of 3.53 (in models 2 and 7). Results are generally consistent across the various dependent variables.

The multivariate findings for the various research questions are presented in the following sections.

\subsubsection{Time (RQ1)}

Both continuous and categorical time variables are significant and positive, confirming bivariate evidence that promotion expectations seem to have increased over time.

\subsubsection{University research intensity ( $R Q 2)$}

The base grouping in the models is 'Group of 8', so the significant negative coefficients imply that promotees in 'New generation/Regional' universities have a smaller number of papers than 'Group of 8' promotees in both ABDC journals (Total $A B D C$ ) and Web of Science indexed journals (TotWoS). Similarly, '60sn70s' promotees also have fewer Web of Science papers than 'Group of 8'. Perhaps more importantly, however, models 6 and 7 suggest that all three groupings have a smaller number of $A^{*}$ plus A-ranked journals than 'Group of 8' promotees. 'Group of 8' seem to demand a larger number of higher quality outputs, on average.

\subsubsection{Discipline differences ( $R Q 3)$}

As in the bivariate analysis, finance promotees typically have more publications than accounting but not a higher number of higher quality journal papers (model 6 with Astar $A$ as dependent variable).

\subsubsection{Publication emphasis in core-discipline journals (RQ4)}

Models 2 and 7 regressions (in Table 5) consider the impact of publishing in core journals on Total $A B D C$ and ' $A *+A$ ' journals, respectively. In model 2 , the effect of accounting (finance) promotees publishing in core accounting (finance) journals is negative, but not statistically significant. However, the interactive term (Fin*Econ\%) confirms that finance promotees who publish in Economic journals typically have a significantly larger volume of outputs (Total $A B D C$ ). By contrast, while the association between the number of ' $A *+A$ ' papers and finance promotee publishing in Economic journals is also 
positive, it is not statistically significant. Focus on core-discipline journals does not seem to influence the number of quality publications at promotion.

\subsubsection{Gender (RQ5)}

None of the models provide any evidence of gender-related differences in prepromotion portfolios.

\subsubsection{Internal/external promotion (RQ6)}

Similarly, there is no evidence of internal promotion requiring more (or less!) publications than external promotion.

\subsubsection{Co-authorship ( $R Q 7)$}

The proportion of sole-authored publications (Soleprop) variable is used to capture the potential effect of co-authorship on promotion portfolios. If coauthored papers are weighted less highly by promotion panels, a higher proportion of sole-authored papers may be rewarded by an expectation of a smaller overall portfolio of papers. This would imply a negative relationship between the number of papers and Soleprop. However, the results show a positive and generally significant relationship. This suggests that a larger proportion of sole-authored papers is associated with a larger pre-promotion portfolio, except for AStarA outputs (models 6 and 7), which are not significant; similar results were found in the prior UK study (Beattie and Goodacre, 2012). While we do not investigate the workings of promotion panels directly in the current study, this result is consistent with the suggestion that co-authorship is not greatly 'penalised' by promotion panels. However, it does not mean that sole authorship is considered unimportant in promotion decisions. The finding would also seem to suggest that working with co-authors does not (necessarily) lead to more outputs.

\subsubsection{Experience (Control)}

In two regressions (models 3 and 4), the number of years as a researchoriented academic (Experience) leads to a significantly larger portfolio at the time of promotion, which is perhaps not too surprising. However, there seems to be no link between experience and the number of quality publications ( $A$ Star $A$ in models 6 and 7).

Overall, the multivariate models confirm the bivariate analysis results. Promotion requirements seem to have increased over the sample period. There are different expectations across the different research-intensity groups, especially in relation to high-quality journal papers. Finance promotees, especially those that publish in Economics, typically have more papers in their 
portfolios than accounting promotees, though not at high-quality levels. However, there is no evidence of differing requirements across gender or for internal promotions. Finally, it would appear that co-authorship per se may not be detrimental to achieving promotion.

\subsection{International comparison of pre-promotion portfolios ( RQ8)}

This paper provides evidence on promotion output portfolios for a third distinct environment following on from prior published evidence for the US and the UK. This provides an opportunity for a preliminary consideration of the international dimension of promotion within an increasingly globalised academic community. Such a comparison is challenging given differences between the studies along several dimensions (e.g. timing, completeness in coverage of the country's academic accounting/finance population and of publication outlets), but can yield some useful observations.

\subsubsection{Specific journals in pre-promotion portfolios}

Detailed analysis of the journals most commonly featuring in Australian finance and accounting promotion portfolios was undertaken ${ }^{13}$ and showed that the 'Top 30' journals account for 43 percent and 58 percent of the total papers in finance and accounting, respectively. This suggests a somewhat wider dispersion of journals in the finance portfolios, reflecting the broader finance/ economics constituents of the finance promotees. A major feature is that both sub-disciplines are fairly heavily oriented towards Australia/Asia-based journals, with 11 and 14 out of the 'Top 30' journals in the finance and accounting lists, respectively. ${ }^{14}$ This 'local' bias is consistent with the prior US and UK

\footnotetext{
${ }^{13}$ The 'Top 10' journals most commonly featuring in pre-promotion portfolios are as follows. For finance promotees (in decreasing order of 'popularity'): Australian Journal of Management; Accounting and Finance; Journal of Banking and Finance; Economic papers; Pacific-Basin Finance Journal; Australian Economic Papers; Accounting Research Journal; Applied Financial Economics; The Economic Record; JASSA. For accounting promotees (in decreasing order of 'popularity'): Australian Accounting Review; Accounting and Finance; Abacus; Accounting Auditing and Accountability Journal; Accounting Research Journal; Accounting and Business Research; Accounting, Organizations and Society; Accounting Forum; Asian Review of Accounting; Managerial Auditing Journal. A full list of the 'Top 30' journals in pre-promotion portfolios for finance and for accounting promotees can be found in the earlier working paper (Goodacre et al., 2017, table 7).

${ }^{14}$ The identification of journal 'location' is challenging. The country of publication is relatively unhelpful, and editor(s) and editorial boards change over time. In many cases, the editorial boards have evolved over the period of this study, often to be more international and reflecting their changing author constituencies. As a result, the 'location' identifications are acknowledged as subjective but are not expected to greatly affect the argument that 'local' publication outlets are important.
}

(C) 2020 The Authors. Accounting \& Finance published by John Wiley \& Sons Australia, Ltd on behalf of Accounting and Finance Association of Australia and New Zealand 
studies, but this has important implications given the perceived wisdom that most top-rated journals are US-based. Indeed, just two and seven journals in the 'Top 30' lists for finance and accounting, respectively, are rated A*; only two journals, Accounting, Organizations and Society (37 occurrences) and Journal of Banking and Finance (32 occurrences), have more than 20 papers featuring in pre-promotion portfolios over the entire dataset period.

\subsubsection{Comparisons with US and UK pre-promotion portfolios}

Table 6 provides comparisons with the prior promotion studies for the US (Fishe, 1998; Glover et al., 2006, 2012) together with equivalent detail for the UK (Beattie and Goodacre, 2012). ${ }^{15}$

First, promotions in the finance sub-discipline are considered. Panel A lists the journals and classifications from Fishe (1998), ${ }^{16}$ together with the number of papers within promotion portfolios for both the US and UK prior studies; i.e. journals represented in the UK pre-promotion portfolios are classified in a manner consistent with Fishe (1998). Panel A also shows the ABDC rank for each journal and the numbers of papers published therein by Australian promoted academics.

Overall, of the total 1,162 papers in the Australian promotion portfolios, 928 were published in the finance-oriented set of journals used by Fishe (1998). However, just 102 (11 percent) of these were published in the Top 15 journals with just one journal in the Fishe list, Journal of Banking and Finance, significantly represented in the Australian pre-promotion portfolios. Thus, as in the UK (final column), there is very limited overlap between the Australian and US portfolios. More importantly perhaps, promotees in Australia and the UK have considerably lower numbers of papers in the Top 4 finance journals than US promotees: a mean of 0.4 per promotee for both Australia $(24 / 61)$ and for the UK (14/33), in comparison with 4.6 for the US; for the Top 15, the

\footnotetext{
${ }^{15}$ A more detailed comparison between Australia and the UK was also undertaken over an identical time period and using an identical research quality proxy (Harvey et al., 2008) to that used in the Beattie and Goodacre (2012) study. Allowing for the different stages in research assessment development, the results suggest that promotion publication expectations were of broadly similar standards in the two countries. Further detail is provided in the earlier working paper (Goodacre et al., 2017, table 9).

${ }^{16}$ Unfortunately, while Fishe (1998) is relatively old, it is the only known US study of finance promotions. Further, it focuses on a sample of the highest research-impact finance departments, in contrast with the fully inclusive coverage of the present and UK studies. Finally, its journal coverage is a little less wide than in the present study. These observations suggest an element of caution when interpreting the results from such a comparison. The classification of Top 4, Top 15 and other journals from Fishe (1998) reflects prior research rankings based on citation-based impact factors. The numbers of publications are derived from tables V-VII in Fishe (1998) but he does not provide sufficient detail to identify the number of publications in the specific journals outside the Top 4.
}

(C) 2020 The Authors. Accounting \& Finance published by John Wiley \& Sons Australia, Ltd on behalf of Accounting and Finance Association of Australia and New Zealand 
equivalent means are 1.7 (Australia: $(24+78) / 61), 2.5$ (UK) compared with 9.3 for the US.

Panel B summarises results for accounting promotions and lists Glover et al.'s Top 25 journals, ${ }^{17}$ the ABDC rank for each journal and the numbers of papers published therein by promoted academics across the three countries.

Overall, of the total 1,344 papers in the Australian accounting promotion portfolios, 276 (20 percent) were published in the journals that Glover et al. perceived as important. Only three journals in the Glover et al. list are significantly represented in the Australian pre-promotion portfolios: Accounting, Organizations and Society, Abacus and Accounting and Business Research. Thus, as with finance, there is very limited overlap between the US and Australian portfolios, consistent with the prior US and the UK comparison (final column). More significantly perhaps, promotees in Australia and the UK have considerably lower numbers of papers in the Top 6 than US promotees: a mean of 0.9 per promotee for Australia $((27+50) / 86)$ and 0.5 for the UK, in comparison with 5.2 for the US.

For context, the international dimensions of the current Australian sample are important. Of the total 147 promotees, ten ( 7 percent) were appointed directly from an overseas university, including two (2 percent) and eight (13 percent) for the accounting and finance sub-samples, respectively. Further, 28 percent of the promotees had a $\mathrm{PhD}$ from an overseas university, representing 16 (19 percent) and 25 (41 percent) of the accounting and finance sub-samples, respectively. The overseas PhDs were most frequently earned in North America with six in the accounting and 15 in the finance sub-samples. Thus, the promotees in finance were far more 'international' than accounting, perhaps reflecting what are generally perceived to be the 'more global' finance and more 'local' accounting disciplines.

Finally, it is interesting to consider the impact of a US-based $\mathrm{PhD}$ on prepromotion publication in the US-based highest ranked journals. In accounting, of the 59 papers in the six US-based A* accounting journals (i.e. excluding Accounting, Organizations and Society), 12 (20 percent) were included in the pre-promotion portfolios of Australian promotees who had US PhDs. In finance, of the 28 papers in the five US-based A* finance journals, 19 (68 percent) were authored by promotees having US PhDs, all from just three

\footnotetext{
${ }^{17}$ In their US studies, Glover et al. $(2006,2012)$ used prior surveys of journal quality to identify a fairly narrow set of 60 journals to proxy for output quality. They group accounting journals in a hierarchy as Top 3, Top 6, Top 15 and Top 25 together with a set of 'high quality' business journals (including finance). While there are differences in the make-up of the latter set of business journals between their two studies, the original 2006 set is used here for consistency, and to facilitate comparison with the summary in the UK study (Beattie and Goodacre, 2012, table 6). Fortunately, raw summary data for the Glover et al. (2012) results are provided on the authors' web site. This enables reconstruction based on the 2006 set of business journals and then combination of the 2006 and 2012 results to form Table 6 here.
}

(C) 2020 The Authors. Accounting \& Finance published by John Wiley \& Sons Australia, Ltd on behalf of Accounting and Finance Association of Australia and New Zealand 
universities (Chicago, Stanford and Wharton). Thus, as might be expected, having a US background, especially in a prestigious university, potentially increases considerably the likelihood of publication in the highest ranked journals, consistent with prior studies of academic publishing generally (Jones and Roberts, 2005).

\section{Summary and conclusions}

Analysis is presented of a study of publication profiles of 147 accounting and finance faculty promoted to professor at Australian universities over the period 1978-2014. Based on median levels, professors required 15 papers in ABDClisted journals, with seven at the highest $\mathrm{A}^{*} / \mathrm{A}$ quality levels for promotion. Promotees were typically 44 years old, with 14 years' academic experience including 9 years post-PhD. Bivariate and multivariate analysis show that the differences in total publications between male/female promotees and between internal/external promotions were not significant. However, finance professors typically had more publications at the time of promotion than accounting professors, though not at the higher quality levels. There were also some significant differences in the timing of promotions. Female promotees were typically older than males and there was a much larger variance in post-PhD period for males. Accounting promotees had greater academic experience than finance promotees, but a shorter period post-PhD.

There is evidence that more research-intensive universities expect a higher number of 'quality' research publications for promotion or appointment to full professor; less research-intensive universities may be willing (at least partially) to substitute publication volume for quality. There is also compelling evidence that both the volume and quality of pre-promotion publications have increased over time. Finally, the results are consistent with the suggestion that coauthorship is not greatly 'penalised' by promotion panels.

The observed restricted cross-over in the promotion journal sets between the US and Australia (and the UK) is consistent both with general patterns of accounting and finance publishing (Jones and Roberts, 2005) and with the view that accounting is (or has been, at least) a local discipline, with a US elite and an 'emerging', mostly European, elite (Lukka and Kasanen, 1996). It also implies that published promotion 'benchmarks' for the US (Glover et al., 2006, 2012) or for the UK (Beattie and Goodacre, 2012) are unlikely to be of significant help or use in the Australian environment. The importance of local norms in promotion decisions has potentially major implications for internationalisation within the accounting and finance discipline. International academics are likely to need time to assimilate and adapt to the local promotion norms; this represents a further challenge for them, and one which has not been highlighted in prior internationalisation studies. Given the location and focus of the 'top-ranked' journals, the results also imply that, ceteris paribus, 'outward' promotional movement from the US (e.g. to 
Australia and/or the UK) is likely to be somewhat easier than migration into the US. Of course, potential salary differentials, cultural and other challenges remain.

So, who will benefit from the findings presented here? The information provided here should be of specific use to aspiring academics seeking to assess the number and quality of publications that might be required for promotion to full professor. Crucially, this is the first time that Australian-local information has been available, which is particularly important given the limited relevance of prior US and UK-based studies. In addition, the information is broken down by institutional type based on research intensity to improve its relevance. It should also provide indicative benchmarks for internal promotion and external appointment panels, which is especially useful for panel members who are non-A\&F specialists with limited knowledge of the A\&F discipline norms. ${ }^{18}$ Given the increasing expectations over time, the more recent results provided in Tables 2 and 3 may prove most useful. Individuals considering movement between institutions with different research intensity should find the separate summaries in Table 3 helpful in indicating the potentially different promotion portfolio expectations.

There is plenty of prior evidence that women are 'under-represented' in more senior academic posts (Winchester et al., 2006; Pyke, 2013; ERA, 2018), and this is also reflected in the present study in the much smaller number of full professor promotions by females within the A\&F discipline. On the other hand, there is no evidence here of gender-related differences in publications for those who actually achieve promotion. In the present study, we do find evidence that females are older at the time of promotion but investigation of reasons for this is beyond the scope of the present study; ${ }^{19}$ further research would be worthwhile to examine whether this might be through choice or necessity. However, the results presented here may provide some encouragement to females (and males) who are perhaps under a misapprehension that they need substantially more (quality) outputs for promotion. Of course, this does not imply that the promotion process is fair to women. As highlighted earlier, it can be argued that any process seeking to measure 'merit' using the publication and grant-based metrics currently adopted is inherently biased against women (White, 2003; Lipton, 2015; Brabazon and Schulz, 2018).

Within the context of increasing academic globalisation, the summaries should be useful to both individuals and institutions. The latter could use the

\footnotetext{
${ }^{18}$ Indeed, there is anecdotal evidence that information from the similar UK study (Beattie and Goodacre, 2012) has been used successfully within appointing/promotion panels by $A \& F$ departments to 'defend' candidates from panel members' unrealistic expectations.

${ }^{19}$ It should also be noted that while females have slightly longer experience $(\sim 1-2$ years, on average) at promotion than males, the difference is not statistically significant. This suggests that females are not particularly slower in accumulating the 'required' outputs.
}

(C) 2020 The Authors. Accounting \& Finance published by John Wiley \& Sons Australia, Ltd on behalf of Accounting and Finance Association of Australia and New Zealand 
information to assist immigrant appointees in achieving their full potential within the new, possibly somewhat alien, environment; the summaries could be useful for mentors when advising newcomers. In turn, individual immigrant academics can benefit from having some idea of what might be expected of them in the new location. More generally, researchers may need to consider promotion expectations as a potentially important additional friction to international movements by academics.

Beattie and Goodacre (2012) framed their study of UK accounting and finance promotions within the theoretical debate concerning the determination of an individual's academic identity and specifically on the relative influence of discipline and institution therein (Henkel, 2005). Their empirical study found that promotion requirements in the UK did not vary significantly across various proxies for institution research intensity, in contrast with prior US studies (Fishe, 1998; Glover et al., 2006). They argued that this supported the view that the academic discipline still maintained a significant influence in the determination of publication requirements for promotion. ${ }^{20}$ The results presented here for Australia show that while more research-intensive universities (e.g., the 'Group of 8') do not require a greater quantity, they do have greater expectations of higher quality publications. This evidence is similar to the US and suggests that Australian institutions maintain control over reward structures including promotion requirements, with limited influence exercisable by academic disciplines. It is consistent with a decline in the role of the academic disciplines in governance, which Marginson and Considine (2000, p. 10) neatly summarise:

The disciplines, and the collegial cultures and networks which sustain them, are often seen as a nuisance by executive managers and outside policy makers. Partly inaccessible to control from above, they can be obstacles to the remaking of institutional structures, the recasting of courses in line with new requirements, and the freer movement of resources ... The other method of tackling the disciplines has been to implement funding and performance systems driving academic work via a common cross-disciplinary model, flattening out the distinctions between different kinds of knowledges, while enabling the university centre to reach directly into the work program and resource base.

In conclusion, some words of caution are required in the use of the indicative benchmarks provided in this study. Glover et al. (2012) highlight two important caveats, both of which also apply here. First, the use of a journal ranking list as a proxy of publication quality is notoriously problematic. Second, it would be inappropriate to focus on the median (or mean) as a proxy

\footnotetext{
${ }^{20}$ Incidentally, in the ten years following the end of the Beattie and Goodacre (2012) data period, disciplinary influence in the UK has been eroded with institutional employment of the tactics that Marginson and Considine (2000) highlighted. This has resulted in concerns being expressed over the very future of the (accounting) discipline (Humphrey and Gendron, 2015; Smith and Urquhart, 2018).
} 
for the minimum publication requirement for promotion. Indeed, using the median would imply that half of the promotees had below the required level, a clearly untenable conclusion. Table 2 provides an indication of the wide variation in promotion publication profiles, including potentially useful quartile measures. Further, as argued earlier, research outputs are just one of the characteristics sought of professors, albeit an important one in many institutions. Depending on an institution's needs, other desirable characteristics may be of greater importance and 'compensate' for apparently 'lower' output levels. Finally, there is a danger that the benchmarks become yet one more (implicit) element of a university performance management system, with all the negative connotations that have been well-documented (Martin-Sardesai et al., 2017); this is certainly not the intention and avoidance will require sensitive usage of the information.

\section{References}

AACSB, 2007, Becoming a Business Professor (AACSB International). Available at: http://www.haas.berkeley.edu/Phd/pdf/BusinessProfessor-full.pdf

ABDC, 2013, ABDC journal quality list 2013. Available at: http://www.abdc.edu.au/da ta/journal_review2013/ABDC_Journal_Quality_List_2013.xls

ABDC, 2019, ABDC journal quality list 2019. Available at: https://abdc.edu.au/research/ abdc-journal-list/.

ACIL Allen Consulting, 2013, Benefits Realisation Review of Excellence in Research for Australia (Australian Research Council, Canberra).

Angervall, P., and D. Beach, 2018, The exploitation of academic work: women in teaching at Swedish universities, Higher Education Policy 31(1), 1-17.

Angervall, P., and D. Beach, 2020, Dividing academic work: gender and academic career at Swedish universities, Gender and Education 32(3), 347-362.

Balasooriya, C., A. Asante, R. Jayasinha, and H. Razee. 2014, Academic mobility and migration: Reflections of international academics in Australia, in: N. Maadad, M. Tight, eds., Academic Mobility (International Perspectives on Higher Education Research), Vol. 11 (Emerald Group Publishing, Bingley, UK), 117-135.

Ballas, A., and V. Theoharakis, 2003, Exploring diversity in accounting through faculty journal perceptions, Contemporary Accounting Research 20(4), 619-644.

Barniv, R., and D. Fetyko, 2001, Changes in the perceived quality of accounting journals, Working Paper (Kent State University).

Beattie, V., and A. Goodacre, 2004, Publishing patterns within the UK accounting and finance academic community, British Accounting Review 36(1), 7-44.

Beattie, V., and A. Goodacre, 2012, Publication records of accounting and finance faculty promoted to professor: evidence from the UK, Accounting and Business Research 42(2), 197-231.

Brabazon, T., and S. Schulz, 2018, Braving the bull: women, mentoring and leadership in higher education, Gender and Education, https://doi.org/10.1080/ 09540253.2018.1544362.

Buchheit, S., D. Collins, and A. Reitenga, 2002, A cross-discipline comparison of toptier academic journal publication rates: 1997-1999, Journal of Accounting Education 20(2), 123-130.

Cappelletto, G., 2010, Challenges facing accounting education in Australia, A Joint Accounting Bodies and AFAANZ commissioned report (AFAANZ, Melbourne).

(C) 2020 The Authors. Accounting \& Finance published by John Wiley \& Sons Australia, Ltd on behalf of Accounting and Finance Association of Australia and New Zealand 
Chan, W., 1996, External recruitment versus internal promotion, Journal of Labor Economics 14(4), 555-570.

Chan, W., 2006, External recruitment and intrafirm mobility, Economic Inquiry 44(1), 169-184.

Chan, K. C., C. H. Chang, J. Y. Tong, and F. Zhang, 2012, An analysis of the accounting and finance research productivity in Australia and New Zealand in 19912010, Accounting and Finance 52(1), 249-265.

Coate, K., and C. K. Howson, 2016, Indicators of esteem: gender and prestige in academic work, British Journal of Sociology of Education 37(4), 567-585.

Coates, H., I. Dobson, D. Edwards, T. Friedman, L. Goedegebuure, and L. Meek, 2009, The Attractiveness of the Australian Academic Profession: A Comparative Analysis (ACER, Hawthorn, Victoria).

Durden, C. H., B. R. Wilkinson, and K. J. Wilkinson, 1999, Publishing productivity of Australian accounting units based on current faculty composition, Pacific Accounting Review 11(1), 1-28.

Dwyer, P. D., 1994, Gender differences in the scholarly activities of accounting academics: an empirical investigation, Issues in Accounting Education 9(2), 231-246.

Endenich, C., and R. Trapp, 2016, Cooperation for publication? An analysis of coauthorship patterns in leading accounting journals, European Accounting Review 25 (3), 613-633.

ERA, 2018, Excellence in Research for Australia. Available at: http://www.arc.gov.au/ excellence-research-australia

Farrell, K., 2009, The use of the title 'Professor': a report of the policies, conventions and practices among Australian Higher Education providers (Centre for the Study of Higher Education, University of Melbourne). Available at: www.cshe.unimelb.edu.au/researc h/policy_dev/docs/HETitleProf.pdf

Fassiotto, M., C. Simard, C. Sandborg, H. Valantine, and J. Raymond, 2018, An integrated career coaching and time-banking system promoting flexibility, wellness, and success: a pilot program at Stanford University School of Medicine, Academic Medicine 93(6), 881-887.

Fishe, R. P. H., 1998, What are the research standards for full professor of finance?, The Journal of Finance 53(3), 1053-1079.

Fogarty, T. J., 2004, Sustained research productivity in accounting: a study of the senior cohort, Global Perspectives on Accounting Education 1(1), 31-58.

Glover, S. M., D. F. Prawitt, and D. A. Wood, 2006, Publication records of faculty promoted at the top 75 accounting research programs, Issues in Accounting Education 21(3), 195-218.

Glover, S. M., D. F. Prawitt, S. L. Summers, and D. A. Wood, 2012, Publication benchmarking data based on faculty promoted at the top 75 US accounting research institutions, Issues in Accounting Education 27(3), 647-670.

Goodacre, A., C. Gaunt, and D. Henry. 2017, Publication records of Australian accounting and finance faculty promoted to full professor, set within an international context, Working Paper. doi: https://doi.org/10.2139/ssrn.3042287.

Greider, C. W., J. M. Sheltzer, N. C. Cantalupo et al, 2019, Increasing gender diversity in the STEM research workforce, Science 366(6466), 692-695.

Guarino, C. M., and V. M. Borden, 2017, Faculty service loads and gender: are women taking care of the academic family? Research in Higher Education 58(6), 672-694.

Guthrie, J., and L. D. Parker, 2014, The global accounting academic: what counts!, Accounting, Auditing and Accountability Journal 27(1), 2-14.

Harvey, C., H. Morris, A. Kelly, eds., 2008, The Association of Business Schools Academic Journal Quality Guide (version 2) (Association of Business Schools, London).

(C) 2020 The Authors. Accounting \& Finance published by John Wiley \& Sons Australia, Ltd on behalf of Accounting and Finance Association of Australia and New Zealand 
Henderson Jr, G. V., G. K. Ganesh, and P. R. Chandy, 1990, Across-discipline journal awareness and evaluation: implications for the promotion and tenure process, Journal of Economics and Business 42(4), 325-351.

Henkel, M., 2005, Academic identity and autonomy in a changing policy environment, Higher Education 49(1-2), 155-176.

Hermanson, D. R., 2008, What I have learned so far: observations on managing an academic accounting career, Issues in Accounting Education 23(1), 53-66.

Hodgson, A., E. Iselin, and C. Martin, 1999, Inputs or outputs? Accounting for the research productivity of Australian accounting departments, Accounting, Accountability and Performance 5(3), 19-48.

Hugo, G., 2008, The demographic outlook for Australian universities' academic staff, Occasional Paper (Council for Humanities, Arts and Social Sciences (CHASS), Adelaide).

Humphrey, C., and Y. Gendron, 2015, What is going on? The sustainability of accounting academia, Critical Perspectives on Accounting 26, 47-66.

Irvine, H. J., L. Moerman, and K. Rudkin, 2010, A green drought: the challenge of mentoring for Australian accounting academics, Accounting Research Journal 23(2), $146-171$.

Jones, M. J., and R. Roberts, 2005, International publishing patterns: an investigation of leading UK and US accounting and finance journals, Journal of Business Finance and Accounting 32(5-6), 1107-1140.

Jordan, C. E., S. J. Clark, and C. E. Vann, 2008, Do gender differences exist in the publication productivity of accounting faculty?, Journal of Applied Business Research 24(3), 77-85.

Kahn, S., 2012, Gender differences in academic promotion and mobility at a major Australian university, Economic Record 88(282), 407-424.

La Trobe University, 2016, Research targets. Available at: http://www.latrobe.edu.au/ab out/vision/research

La Trobe University, 2020, Academic promotions: teaching and research. Available at: https://policies.latrobe.edu.au/download.php?associated $=1 \& i d=101 \&$ version $=1$

Lipton, B., 2015, A new 'ERA' of women and leadership: the gendered impact of quality assurance in Australian higher education, Australian Universities' Review 57(2), 60-70.

Lukka, K., and E. Kasanen, 1996, Is accounting a global or a local discipline? Evidence from major research journals, Accounting, Organizations and Society 21(7-8), 755773.

Marginson, S., 1997, Competition and contestability in Australian Higher Education, 1987-1997, Australian Universities' Review 40(1), 5-14.

Marginson, S., 2006, Dynamics of national and global competition in higher education, Higher Education 52(1), 1-39.

Marginson, S., and M. Considine, 2000, The Enterprise University: Power, Governance and Reinvention in Australia (Cambridge University Press, Cambridge, UK).

Martin-Sardesai, A., H. Irvine, S. Tooley, and J. Guthrie, 2017, Accounting for research: academic responses to research performance demands in an Australian university, Australian Accounting Review 27(3), 329-343.

Milne, M. J., R. W. Adler, and A. C. MacGregor, 1999, A critical commentary on Wilkinson and Durden's (1998) measures of accounting publishing productivity, Pacific Accounting Review 11(1), 29-44.

Moodie, G., 2012, Types of Australian universities. Available at: http://www.acade mia.edu/310547/Types_of_Australian_universities

Nathan, S., D. R. Hermanson, and R. H. Hermanson, 1998, Co-authoring in refereed journals: views of accounting faculty and department chairs, Issues in Accounting Education 13(1), 79-92.

(C) 2020 The Authors. Accounting \& Finance published by John Wiley \& Sons Australia, Ltd on behalf of Accounting and Finance Association of Australia and New Zealand 
Norgaard, C. T., 1989, A status report on academic women accountants, Issues in Accounting Education 4(1), 11-28.

Oltheten, E., V. Theoharakis, and N. G. Travlos, 2005, Faculty perceptions and readership patterns of finance journals: a global view, Journal of Financial and Quantitative Analysis 40(1), 223-239.

Parker, L., 2011, University corporatisation: driving redefinition, Critical Perspectives on Accounting 22(4), 434-450.

Parker, L., J. Guthrie, and R. Gray, 1998, Accounting and management research: passwords from the gatekeepers, Accounting, Auditing and Accountability Journal 11 (4), 371-406.

Plumlee, R. D., S. J. Kachelmeier, S. A. Madeo, J. H. Pratt, and G. Krull, 2006, Assessing the shortage of accounting faculty, Issues in Accounting Education 21(2), $113-125$.

Potts, A. 2014, Patterns and persistence in academic migration: 40 years of Australian academic migration, in: N. Maadad, M. Tight, eds., Academic Mobility (International Perspectives on Higher Education Research), Vol. 11 (Emerald Group Publishing, Bingley, UK), 95-115.

Probert, B., 2005, 'I just couldn't fit it in': gender and unequal outcomes in academic careers, Gender, Work and Organization 12(1), 50-72.

Pyke, J., 2013, Women, choice and promotion or why women are still a minority in the professoriate, Journal of Higher Education Policy and Management 35(4), 444-454.

Rama, D. V., K. Raghunandan, L. B. Logan, and B. V. Barkman, 1997, Gender differences in publications by promoted faculty, Issues in Accounting Education 12(2), 353-365.

Schinski, M., A. Kugler, and W. Wick, 1998, Perceptions of the academic finance profession regarding publishing and the allocation of credit in coauthorship situations, Financial Practice and Education 8, 60-68.

Shanghai Jiao Tong University, 2016, Academic Ranking of World Universities. Available at: http://www.shanghairanking.com

Smith, S. J., and V. Urquhart, 2018, Accounting and finance in UK universities: academic labour, shortages and strategies, British Accounting Review 50(6), 588-601.

Stewart, P., M. Ornstein, and J. Drakich, 2009, Gender and promotion at Canadian universities, Canadian Review of Sociology/Revue canadienne de sociologie 46(1), 5985.

Streuly, C. A., and C. L. Maranto, 1994, Accounting faculty research productivity and citations: are there gender differences?, Issues in Accounting Education 9(2), 247-258.

Subramaniam, N., 2003, Factors affecting the career progress of academic accountants in Australia: cross-institutional and gender perspectives, Higher Education 46(4), 507542.

Swanson, E. P., 2004, Publishing in the majors: a comparison of accounting, finance, management and marketing, Contemporary Accounting Research 21(1), 223-255.

Teichler, U., A. Arimoto, and W. K. Cummings, 2013, The Changing Academic Profession: Major Findings of a Comparative Study (Springer, Dordrecht).

Tenopir, C., and D. W. King, 2014, The growth of journals publishing, in: B. Cope, A. Phillips, eds., The Future of the Academic Journal, 2nd edn (Chandos Publishing, Oxford), 159-178.

Thomas, J., C. Thomas, and K. Smith, 2019, The challenges for gender equity and women in leadership in a distributed university in regional Australia, Social Sciences 8 (6), 165.

Tower, G., R. Desai, B. Carson, and S. Cheng, 2005, Better understanding research performance, Asian Review of Accounting 13(2), 51-67.

(C) 2020 The Authors. Accounting \& Finance published by John Wiley \& Sons Australia, Ltd on behalf of Accounting and Finance Association of Australia and New Zealand 
Tucker, B. P., L. D. Parker, and K. A. Merchant, 2016, With a little help from our friends: an empirical investigation of co-authoring in accounting research, British Accounting Review 48(2), 185-205.

University of Newcastle, 2016, International research performance. Available at: http:// www.newcastle.edu.au/research-and-innovation/global-leadership/international-resea rch-performance

University of South Australia, 2019, Academic promotions: guidelines for 2019 applicants. Available at: https://i.unisa.edu.au/siteassets/human-resources/ptc/files/ guidelines/academic-promotion/2019_academic-promotion-guidelines.pdf

Von Tunzelmann, N., and E. K. Mbula. 2003, Changes in research assessment practices in other countries since 1999. Report for UK HEFCE. Available at: http://www.rareview.ac.uk/reports/prac/changingpractices.pdf

Welch, A. R., 1997, The peripatetic professor: the internationalisation of the academic profession, Higher Education 34(3), 323-345.

Welch, A.2012, Academic salaries, massification and the rise of an underclass in Australia, in: P. G. Altbach, L. Reisberg, M. Yudkevich, G. Androushchak, I. F. Pacheco, eds., Paying the Professoriate: A Global Comparison of Compensation and Contracts (Taylor \& Francis, London), 61-71.

White, K., 2003, Women and leadership in higher education in Australia, Tertiary Education and Management 9(1), 45-60.

Wilkinson, B. R., C. H. Durden, and K. J. Wilkinson, 2003, A Tobit analysis of accounting faculty publishing productivity in Australian and New Zealand universities, Advances in Accounting Behavioral Research 6, 173-186.

Winchester, H., S. Lorenzo, L. Browning, and C. Chesterman, 2006, Academic women's promotions in Australian universities, Employee Relations 28(6), 505-522.

(C) 2020 The Authors. Accounting \& Finance published by John Wiley \& Sons Australia, Ltd on behalf of Accounting and Finance Association of Australia and New Zealand 